Review

\title{
Organic Dyes versus Adsorption Processing
}

\author{
Francisco J. Alguacil (D) and Félix A. López *(D) \\ National Center for Metallurgical Researcher (CENIM), Spanish National Research Council (CSIC), \\ Avda. Gregorio del Amo 8, 28040 Madrid, Spain; fjalgua@cenim.csic.es \\ * Correspondence: f.lopez@csic.es; Tel.: +34-915-538-900
}

check for updates

Citation: Alguacil, F.J.; López, F.A. Organic Dyes versus Adsorption Processing. Molecules 2021, 26, 5440. https://doi.org/10.3390/ molecules 26185440

Academic Editor:

Monika Wawrzkiewicz

Received: 26 July 2021

Accepted: 3 September 2021

Published: 7 September 2021

Publisher's Note: MDPI stays neutral with regard to jurisdictional claims in published maps and institutional affiliations.

Copyright: (c) 2021 by the authors. Licensee MDPI, Basel, Switzerland. This article is an open access article distributed under the terms and conditions of the Creative Commons Attribution (CC BY) license (https:// creativecommons.org/licenses/by/ $4.0 /)$.

\begin{abstract}
Even in the first quarter of the XXI century, the presence of organic dyes in wastewaters was a normal occurrence in a series of countries. As these compounds are toxic, their removal from these waters is a necessity. Among the separation technologies, adsorption processing appeared as one of the most widely used to reach this goal. The present work reviewed the most recent approaches (first half of the 2021 year) regarding the use of a variety of adsorbents in the removal of a variety of organic dyes of different natures.
\end{abstract}

Keywords: organic dyes; adsorption; removal; wastewaters; environment

\section{Introduction}

Several industries need to use organic dyes in their respective processes. However, the usefulness of these dyes, including either natural or synthetic, presents an important odd point: they are toxic for life, thus their presence in waters, wastewaters, and in general liquid effluents must be avoided to obey the regulatory discharge laws for these compounds and to decrease the risk of possible contact with humans.

Various technologies seem to be appropriate for the treatment of organic dye-bearing waters but among them, adsorption processing appears as one of the most used, probably due to its apparent operational simplicity and myriad of potential adsorbents which can be used in this environmental issue.

The importance of these adsorptive methodologies in the removal of organic dyes from waters is reflected in the number of investigations and reviews published in the years. Recently, several reviews about the use of a given type of adsorbents in this role have been published, including silica-based mesoporous materials of the M41S and SBA-n families [1], different types of graphene-based materials [2,3], biochars [4], metal-organic frameworks (MOF) [5,6], various types of polymeric nanofibers [7], metal-doped porous carbon materials [8], and activated carbon fibers [9].

The present work reviews very recent publications (first half of the 2021 year) regarding the use of adsorbents in the removal of organic dyes from waters and, in many cases, the investigations are carried out on synthetic solutions, but there are also some examples in which adsorbents are used on real waters. Readers must be aware that this review does not include publications regarding desorption-degradation processing of these toxic chemicals.

\section{Adsorbents for the Removal of Anionic Dyes from Waters}

A green route was used to prepare $\mathrm{ZnO}: \mathrm{NiO}$ nanocomposites $(\mathrm{Z}: \mathrm{N})$ using the Neem leaf extract as a stabilizing agent [10]. Four different samples with three different $\mathrm{ZnO}: \mathrm{NiO}$ ratios were prepared, namely $3 \mathrm{Z}: 1 \mathrm{~N}, 1 \mathrm{Z}: 1 \mathrm{~N}, 1 \mathrm{Z}: 3 \mathrm{~N}$, and 1Z:1N without leaf extract. The different nanocomposites were used for the adsorption of methyl orange from aqueous solutions and some of the results are summarized in Table 1.

With the adsorbent containing an excess of $\mathrm{NiO}(1 \mathrm{Z}: 3 \mathrm{~N})$, a maximum in methyl orange capacity was reached. It can also be observed that the addition of the Neem leaf extract 
improved the dye uptake. In all the cases, the uptakes derived by the model (Equation (1)) were in accordance with the corresponding experimental values. The adsorption followed the pseudo-first kinetic equation, which in the published manuscript was written as:

$$
\log \left([\mathrm{MO}]_{\mathrm{ad}, \mathrm{e}}-[\mathrm{MO}]_{\mathrm{ad}, \mathrm{t}}\right)=\log [\mathrm{MO}]_{\mathrm{ad}, \mathrm{e}}-\mathrm{K}_{\mathrm{p} 1} \mathrm{t}
$$

where $\mathrm{K}_{\mathrm{p} 1}$ represents the model constant. The procedure followed to reuse the adsorbent was as follows: $0.1 \mathrm{M} \mathrm{NaOH}$ (desorption), $0.1 \mathrm{M} \mathrm{HNO}_{3}$ (neutralizing), washing with water until $\mathrm{pH}$ 7, and lastly drying.

Table 1. Dye uptakes onto the various adsorbents tested.

\begin{tabular}{ccc}
\hline Adsorbent & {$\left[\mathbf{M O}_{\text {experimental }}, \mathbf{m g} / \mathbf{g}\right.$} & {$[\mathbf{M O}]_{\text {model }}, \mathbf{~ m g} / \mathbf{g}$} \\
\hline 1Z:1N without extract & 4.4 & 4.4 \\
3Z:1N & 5.4 & 5.9 \\
1Z:1N & 5.1 & 5.8 \\
1Z:3N & 12 & 11 \\
\hline
\end{tabular}

Temperature: $20^{\circ} \mathrm{C}$; $\mathrm{pH}$ : 4 ; and time: $2 \mathrm{~h}$. Abbreviation: $\mathrm{MO}$, methyl orange.

A surface modification of mesoporous carbon (MC), based on a Diels-Alder [4 + 2] cycloaddition, and the multicomponent Radziszewski reactions generated a MC@PIL composite [11]. This adsorbent was used to adsorb Congo red at various experimental conditions including: contact time, concentration, $\mathrm{pH}$, and temperature. The investigation demonstrated that the dye was adsorbed on the composite within 10 min of contact, whereas the adsorption capacity was near $331 \mathrm{mg} / \mathrm{g}$, which was greater than that found with the pristine mesoporous carbon. In this work, the experimental data were fitted to the non-linear forms of the pseudo-second order kinetic model (Equation (2)) and the Langmuir isotherm (Equation (6)):

$$
\begin{gathered}
{[\mathrm{CR}]_{\mathrm{ad}, \mathrm{t}}=\frac{\mathrm{K}_{\mathrm{p} 2}[\mathrm{CR}]_{\mathrm{ad}, \mathrm{e}}^{2}}{1+\mathrm{K}_{\mathrm{p} 2}[\mathrm{CR}]_{\mathrm{ad}, \mathrm{e}}^{\mathrm{t}}}} \\
{[\mathrm{CR}]_{\mathrm{ad}, \mathrm{e}}=[\mathrm{CR}]_{\mathrm{ad}, \mathrm{m}} \frac{\mathrm{K}_{\mathrm{L}}[\mathrm{CR}]_{\mathrm{aq}, \mathrm{e}}}{1+\mathrm{K}_{\mathrm{L}}[\mathrm{CR}]_{\mathrm{aq}, \mathrm{e}}}}
\end{gathered}
$$

where $[C R]$ represents the Congo red concentration. Desorption was carried out as written in the published article: " ... contained a certain proportion of water/ethanol (45\%) and a few drops of $1 \mathrm{M} \mathrm{NaOH}$ solution during one hour". Under continuous use and after three cycles, the desorption rate decreased from $87 \%$ to $81 \%$ and thus the adsorption capacity decreased from $331 \mathrm{mg} / \mathrm{g}$ until near $200 \mathrm{mg} / \mathrm{g}$.

Being a natural, low-cost, and eco-friendly material, naturally occurring alumina particles were used as an adsorbent for the removal of eriochrome black $\mathrm{T}$ (anionic dye) from an aqueous environment [12]. The adsorption process can be controlled for by electrostatic attractions, the experimental data were well-described by the pseudo-second order kinetic model, and the adsorption isotherms fitted well with the Langmuir isotherm. The maximum adsorption capacity was found to be $45 \mathrm{mg} / \mathrm{g}$, which corresponded to $71 \%$ of the dye removal. The adsorption was endothermic and spontaneous. The desorption procedure and reconditioning of the adsorbent for its reuse followed several steps: (i) desorption with $0.1 \mathrm{M} \mathrm{NaOH}$ solution over the course of $3 \mathrm{~h}$; (ii) washing with $\mathrm{HCl}$ and water; and (iii) drying at $60{ }^{\circ} \mathrm{C}$ for $24 \mathrm{~h}$. Over four consecutive cycles, adsorption decreased in a continuous form from $43 \mathrm{mg} / \mathrm{g}$ to near $36 \mathrm{mg} / \mathrm{g}$ and at the same time, the desorption efficiency decreased from $71 \%$ to $60 \%$ after the fourth cycle.

$\mathrm{ZnO}-\mathrm{CdWO}_{4}$ nanoparticles had been synthesized by a green method with lemon leaf extract to favorably anchor functional groups on their surfaces [13]. The prepared nanoparticles were used as an adsorbent of Congo red. The adsorption process was found 
to be exothermic and spontaneous, and followed the Freundlich isotherm model. The Boyd plot had been used as a confirmatory tool to fit the adsorption kinetics data alongside both the intraparticle diffusion and pseudo-second-order models. No desorption data were included in this work.

In the next reference [14], the investigation was not carried out on an industrial wastewater but on a synthetic solution of water containing the organic dye, which they specified in the abstract. The metal-organic framework Fe-MIL- $88 \mathrm{NH}_{2}$, with the composition $\left(\mathrm{Fe}_{3} \mathrm{O}\left(\mathrm{OH}_{2}\right)_{3} \mathrm{Cl}\left(\mathrm{NH}_{2}-\mathrm{BDC}\right)_{3} \cdot 9.5 \mathrm{H}_{2} \mathrm{O}\right)$, was used to remove Congo red $(5-60 \mathrm{mg} / \mathrm{L})$ from water. The Temkin adsorption isotherm model and pseudo-second kinetic model best-fitted the experimental data. The removal of the dye from the water responded to a chemical adsorption process. This adsorbent presented a certain grade of selectivity with respect to Congo red and in contrast to both methyl orange and methylene blue. Desorption of the loaded Congo red was done using ethanol and after four cycles the removal efficiency was fixed above $83 \%$.

The mixture of chitosan beads cross-linked with glutaraldehyde was used to investigate the adsorption of reactive blue 4 from an aqueous solution [15]. The response surface methodology was applied to evaluate the concentration of chitosan, glutaraldehyde, and sodium hydroxide on the swelling degree in the adsorbent. The design with $\mathrm{r}^{2}$ equal to 0.8634 allowed for to the best concentrations including: chitosan $(3.3 \% w / v)$, glutaraldehyde $(1.7 \% v / v)$, and $\mathrm{NaOH}(1.3 \mathrm{M})$. However, for practical purposes aiming to decrease the viscosity and facilitate the formation of the beads, the real chitosan concentration used in the experiments was equal to $3.0 \%$. In the case of the dye adsorption, the best conditions $\left(\mathrm{r}^{2}=0.8280\right)$ were: $\mathrm{pH} 2$, adsorbent dosage of $0.6 \mathrm{~g}$, and initial dye concentration of $5 \mathrm{mg} / \mathrm{L}$. The adsorption process was controlled for mainly by chemisorption interactions and responded well to the Elovich model, expressed as

$$
[\mathrm{RB} 4]_{\mathrm{ad}, \mathrm{e}}=\frac{1}{\beta} \ln \alpha \beta+\frac{1}{\beta} \ln \mathrm{t}
$$

And the Freundlich isotherm. In Equation (4), $\alpha$ represents the initial adsorption rate and $\beta$ represents the desorption constant; this last parameter also corresponds to the extent of the surface coverage and activation energy for a chemisorption mechanism. No desorption data were included in the investigation.

The adsorption of methyl orange and fluorescein sodium was investigated using three 3D coordination polymers: A, (CPs) and $[\mathrm{Cd}(\mathrm{L})(\mathrm{bifu})]_{\mathrm{n}} ; \mathrm{B}:\left[\mathrm{Zn}(\mathrm{L})(\mathrm{bimb})_{0.5}\right]_{\mathrm{n}}$; and C: $\left\{[\mathrm{Ni}(\mathrm{L})(\mathrm{bifu})]\left(\mathrm{H}_{2} \mathrm{O}\right)_{4}\right\}$, being H2L 4,4'-(phenylazanediy1)dibenzoic acid, bifu: 2,7-bis(1imidazoly)fluorene, and bimb: 1,4-bis(imidazol-1-yl)) [16]. The 3D network structures were different considering A crystallized in a monoclinic space group P21/n; B crystallized in a orthorhombic space group Pbca; and C crystallized in a triclinic space group P-1. The adsorbents were not suitable for the adsorption of methylene blue and rhodamine B. No desorption data were included in this work.

A series of enantiomorphic $\mathrm{Pb}$-based metal-organic coordination polymers, i.e., $\left[\mathrm{Pb}((\mathrm{R}, \mathrm{R})-\mathrm{TBA})\left(\mathrm{H}_{2} \mathrm{O}\right)\right] \cdot 1.7 \mathrm{H}_{2} \mathrm{O}(\mathrm{R} 1)$ and $\left[\mathrm{Pb}((\mathrm{S}, \mathrm{S})-\mathrm{TBA})\left(\mathrm{H}_{2} \mathrm{O}\right)\right] \cdot 1.7 \mathrm{H}_{2} \mathrm{O}(\mathrm{S} 1)(\mathrm{TBA}=1,3,5-$ triazin-2(1H)-one-4,6-bis(alanyl)), had been synthesized through the solvothermal reactions [17]. Compounds R1 and S1 crystallized in the chiral space group, P212121, revealing infinite unidimensional (1D) chain structures. These complexes showed a selective adsorption of anionic organic dyes (e.g., Congo red) via a host-guest hydrogen bonding interaction, electrostatic attraction, and $\pi-\pi$ stacking between the $\mathrm{Pb}$ complex and the organic dye. Dye uptake reached $140 \mathrm{mg} / \mathrm{g}$ and followed the pseudo-second order kinetic model. No desorption data were included in this work.

Methyl blue was removed from water by ordered mesoporous silica SBA-15 [18]. The adsorbent was synthesized by silica functionalization with $\beta$-cyclodextrin via amide linkage. The adsorption properties of this adsorbent were investigated under several variables: contact time, $\mathrm{pH}$, ionic strength, temperature, and salt. The maximum dye adsorption capacity was of $1791 \mathrm{mg} / \mathrm{g}$, as the adsorption followed the non-linear forms of 
both the Langmuir and Freundlich isotherms; thus, the dye uptake was attributed both to homogeneous and heterogeneous mechanisms. The organic dye uptake presented a slight decrease in the $2-5 \mathrm{pH}$ range as well as an important decrease from neutral and alkaline values. The adsorption capacity towards the dye was explained in terms of the tailored host-guest interaction between the $\beta$-cyclodextrin cavity and the aromatic moiety of the dye, as well as in combination with the electrostatic attraction between amine groups and the sulfonated group present in the organic dye. Ethanol was used to desorb the dye and there was a continuous decrease in the uptake capacity, specifically up to six cycles.

The ternary $\mathrm{Cu} / \mathrm{Cu}_{2} \mathrm{O} / \mathrm{C}$ composite, presenting anionic dye adsorption capacities, was synthesized by a solvent-free method [19]. The maximum monolayer adsorption capacity of $\mathrm{Cu} / \mathrm{Cu}_{2} \mathrm{O} / \mathrm{C}$ for methyl orange and acid blue 93 was 1409 and $5385 \mathrm{mg} / \mathrm{g}$, respectively. In addition, the $\mathrm{Cu} / \mathrm{Cu}_{2} \mathrm{O} / \mathrm{C}$ composite could selectively adsorb anionic dyes (methyl orange and acid blue 93) from a mixture of different dyes. The increase in the adsorbent dosage allowed to achieve the equilibrium at shorter reaction times, whereas maximum uptakes (99\%) were reached at $\mathrm{pH} 4.7$, decreasing this value until $50 \%$ at $\mathrm{pH} 11$. The various experimental data indicated that the adsorption process followed the Langmuir isotherm and the pseudo-second-order kinetic model, whereas the removal of both dyes from the water was spontaneous and exothermic in nature. Based on the experimental results and the characterization of the composite, it could be concluded that a physical and chemical synergism effect existed in the adsorption process, and chemisorption was the main rate-limiting step. Desorption was achieved using hot water $\left(90^{\circ} \mathrm{C}\right)$ and ethanol after three cycles, and the removal rate decreased from $99 \%$ to $75 \%$; this decrease was attributable to (i) the partial oxidation of $\mathrm{Cu}_{2} \mathrm{O}$ or $\mathrm{Cu}$ on the surface of the composite and the fact that (ii) the desorption was not complete.

Combustion and gel calcination operations were used to prepare magnetic $\mathrm{Zn}_{0.3} \mathrm{Cu}_{0.7}$ $\mathrm{Fe}_{2} \mathrm{O}_{4}$ nanoparticles (50-80 nm) and adsorb reactive red 2BF [20]. Experimental data using dye concentrations in the $100-400 \mathrm{mg} / \mathrm{L}$ range fitted to the non-linear pseudo-secondorder kinetic model, whereas the Temkin isotherm explained the experimental loading equilibrium data; thus, adsorption was due to a monolayer-multilayer hybrid adsorption mechanism. The dye adsorption capacity reached $135 \mathrm{mg} / \mathrm{g}$, though it was $\mathrm{pH}$-dependant, with a maximum adsorption in the $1-3 \mathrm{pH}$ range and a progressive decay near the zero adsorption at $\mathrm{pH} 11$. Desorption can be carried out under alkaline conditions, although a continuous decrease in the adsorption rate, from $100 \%$ to near $80 \%$, was observed after ten cycles. This decrease was attributable to the nanoparticles agglomerated and the adsorption sites gradually decreased, in addition to the gradual loss of the adsorbent material.

A polyurethane/polyaniline material that can be used as an adsorbent for azo dyes from aqueous solutions was developed [21]. This adsorbent was generated by incorporating polyaniline into the surface of a macroporous polyurethane foam by a chemical polymerization methodology. The adsorption capacity of the material was evaluated against the removal of methyl orange at various $\mathrm{pH}$ values, contact times, and initial concentrations. The adsorption reached an equilibrium after $30 \mathrm{~h}$, following the Elovich and intraparticular diffusion models. The maximum experimental adsorption capacity was of $255 \mathrm{mg} / \mathrm{g}$ at $\mathrm{pH}$ 5, whereas the data fitted the Sips isotherm:

$$
[\mathrm{MO}]_{\mathrm{ad}, \mathrm{e}}=\frac{[\mathrm{MO}]_{\mathrm{ad}, \mathrm{m}} \mathrm{K}_{\mathrm{S}}[\mathrm{MO}]_{\mathrm{aq}, \mathrm{e}}^{\mathrm{ns}}}{1+\mathrm{K}_{\mathrm{S}}[\mathrm{MO}]_{\mathrm{aq}, \mathrm{e}}^{\mathrm{ns}}}
$$

where $\mathrm{K}_{\mathrm{S}}$ represents the equilibrium constant and ns represents a surface heterogeneity parameter. Desorption was investigated using $0.1 \mathrm{M} \mathrm{HCl}$ solutions; thus, due to the electrostatic repulsion, the dye was removed from the adsorbent. After ten cycles, the adsorbent maintained its desorption performance, though the adsorption rate decreased from $100 \%$ to $60 \%$ and this decrease was attributed to loss of adsorbent due to agitation and material management. 
The one-step hydrothermal method allowed for the production of flower-like $\mathrm{Mg} / \mathrm{Fe}$ layered double-oxide nanospheres and the adsorbent was used to decrease methyl blue and Congo red levels in aqueous solutions [22]. The removal of $99 \%$ of the initial dye concentration occurred quickly in the case of methyl blue, requiring $5 \mathrm{~min}$, while the case of Congo red required $25 \mathrm{~min}$. Following the Langmuir isotherm, in the $20-40{ }^{\circ} \mathrm{C}$ range, maximum removal capacities $\left(25^{\circ} \mathrm{C}\right)$ varied from $1250 \mathrm{mg} / \mathrm{g}$ in the case of Congo red and $2000 \mathrm{mg} / \mathrm{g}$ for methyl blue; these results were attributable to the chemical adsorption between both anionic dyes and cationic adsorbent nanospheres through strong electrostatic interactions. The adsorption of both dyes followed the pseudo-second-order kinetic model in the endothermic and spontaneous adsorption processes. In the case of methyl blue, desorption was done by water (three washes) and the adsorption efficiency (above 99\%) was maintained for five cycles.

Akaganeite nanoparticles (average size $50 \mathrm{~nm}$ ) were synthesized by using microwaves to remove Congo red from an aqueous phase [23]. Experimental results showed that the adsorption kinetics fitted the non-linear pseudo-second-order equation, whereas adsorption equilibrium values, at various temperatures, generally best-fitted the non-linear Langmuir isotherm, with the maximum adsorption capacity of more than $150 \mathrm{mg} / \mathrm{g}$ at pH 5.5. Dye uptake onto the adsorbent was spontaneous and endothermic. No desorption data were included in this work.

A composite material of magnetic cross-linked chitosan-glyoxal/ $\mathrm{ZnO} / \mathrm{Fe}_{3} \mathrm{O}_{4}$ nanoparticles (CS-G/ $\mathrm{ZnO} / \mathrm{Fe}_{3} \mathrm{O}_{4} \mathrm{NPs}$ ) was used in the adsorption of reactive blue 19 [24]. The compound was firstly produced by first Schiff's base magnetic cross-linked chitosanglyoxal $/ \mathrm{Fe}_{3} \mathrm{O}_{4}$ composite (CS-G/ $/ \mathrm{Fe}_{3} \mathrm{O}_{4}$ ) synthesis and then further by the loading of zinc oxide nanoparticles into the polymeric matrix. Using dye concentrations in the $50-300 \mathrm{mg} / \mathrm{L}$ range, the adsorption results were well-described by the pseudo-secondorder kinetic model and Freundlich isotherm, with the maximum adsorption capacity of $363 \mathrm{mg} / \mathrm{g}$ at $60^{\circ} \mathrm{C}$. Dye uptake was attributable to several types of interactions including (i) electrostatic attractions, (ii) hydrogen bonding, and (iii) $n-\pi$ interactions. Again, the desorption step was not considered in this work.

A type of hierarchical porous zeolitic imidazole framework-67@ layered doublehydroxide, ZIF-67@LDH, was developed; the material consisted of nanocubes decorated with nanosheets [25]. This material was used in the adsorption of methyl orange and alizarin red $\mathrm{S}$ at various $\mathrm{pH}$ values, temperatures, and contact times. Adsorption equilibrium was attained within $100 \mathrm{~min}$ at $30^{\circ} \mathrm{C}$, with a slight increase of the adsorption capacity with the increase of the temperature $\left(20-40^{\circ} \mathrm{C}\right)$. The adsorption followed the pseudo-second-order kinetic model and Langmuir isotherm, which confirmed the monolayer adsorption of the dye onto the adsorbent. Maximum capacities were $793 \mathrm{mg} / \mathrm{g}$ at $\mathrm{pH} 4$ (alizarin red S) and $316 \mathrm{mg} / \mathrm{g}$ at $\mathrm{pH} 6$ (methyl orange). Desorption was accomplished by the use of $0.1 \mathrm{M}$ of $\mathrm{HCl}$ solution, followed by a second wash with ethanol and water. After four cycles, the adsorbent presented a continuous decrease in its adsorption capacity.

The material, Ag@ZIF-67, was used in the removal of methyl orange from polluted water [26]. Dye uptake increased from $\mathrm{pH} 2$ to $\mathrm{pH} 6$, with a further decrease until $\mathrm{pH} 11$. This uptake also increased with temperature in the $10-30{ }^{\circ} \mathrm{C}$ range, with no variation at $40{ }^{\circ} \mathrm{C}$. The experimental data fitted to the pseudo-second-order kinetic and Langmuir models, with the maximum adsorption capacity of $1146 \mathrm{mg} / \mathrm{g}$. Dye desorption used $0.1 \mathrm{M}$ of $\mathrm{HCl}$ solution and a continuous decrease in the adsorption-desorption capacity was observed, e.g., 99\% adsorption (first cycle) against 70-80\% (fifth cycle).

As pristine carbon materials poorly remove organic dyes from waters, tuning the carbon with magnetic compounds tended to reverse the above situation. Thus, carbon biomass from the seeds of Moringa oleifera was mixed with manganese ferrite and the final material was investigated to adsorb indigo carmine, acid blue 158, and reactive blue 4 [27]. Dye uptake onto the adsorbent was $34 \mathrm{mg} / \mathrm{g}, 35 \mathrm{mg} / \mathrm{g}$, and $32 \mathrm{mg} / \mathrm{g}$ for the above dyes, respectively, with the maximum adsorption occurring at a $\mathrm{pH}$ near 3 . In addition, in the three cases, the adsorption followed the pseudo-second-order model and 
Freundlich isotherm in the endothermic and spontaneous processes. In the presence of co-existing anions, chloride, sulphate, or bicarbonate, the adsorption slightly decreased, this attributable to the competition with the dye molecules for vacant sites of the adsorbent. The adsorbent worked via electrostatic attraction, hydrogen bonding, and $\pi-\pi$ interaction. Desorption was performed using $0.1 \mathrm{M}$ of $\mathrm{NaOH}$ solution, with a relationship of $50 \mathrm{~mL}$ desorption solution/100 $\mathrm{mg}$ of adsorbent loaded with dye. After five cycles, the efficacy of the adsorbent decreased, probably due to the increasing clustering of the adsorbent surface. Some of these results are shown in Table 2.

Table 2. Efficacy of the adsorbent after cycles of adsorption-desorption.

\begin{tabular}{cccccc}
\hline Dye & 1st Cycle & 2nd Cycle & 3rd Cycle & 4th Cycle & 5th Cycle \\
\hline Reactive blue 4 & 85 & 83 & 70 & 65 & 60 \\
Indigo carmine & 90 & 85 & 80 & 73 & 65 \\
Acid blue 158 & 93 & 85 & 80 & 65 & 63 \\
\hline
\end{tabular}

Alginate-reinforced reduced graphene oxide@hydroxyapatite hybrids have been synthesized via the co-precipitation method and investigated as adsorbents towards reactive blue 4 , acid blue 158, and indigo carmine from aqueous solutions [28]. The corresponding uptake was of $46 \mathrm{mg} / \mathrm{g}, 48 \mathrm{mg} / \mathrm{g}$, and $47 \mathrm{mg} / \mathrm{g}$, respectively. Within this adsorbent, the $\mathrm{pH}$ value to generate the maximum adsorption was 6-7 and the dyes removal was both endothermic and spontaneous. The presence of bicarbonate in the solution did not affect the adsorption properties; however, if chloride or sulphate anions were present in the water, the adsorption efficiency would decrease due to interactions with the adsorbent surface. Dyes' uptake was attributable to (i) electrostatic interactions, (ii) surface complexation, and (iii) hydrogen bonding mechanisms. Desorption was carried out with $0.1 \mathrm{M}$ of $\mathrm{NaOH}$ solutions, decreasing the adsorption capacity from the first to the fifth cycle in a continuous form.

Zeolitic imidazolate framework-67 was used as a template to fabricate hollow LDH nanocages and the template was consumed during the formation of the nanomaterial. The nanocages were composed of NiCo-LDH nanosheets that maintained the dodecahedron shape of the template [29]. The resultant material was used to remove Congo red under various experimental variables. Dye adsorption was attributable to a chemisorption process and followed the pseudo-second-order kinetic model and Langmuir isotherm in the $25-45^{\circ} \mathrm{C}$ temperature range. With a maximum adsorption at $\mathrm{pH} 7$, the maximum capacity increased with the increase of the temperature, e.g., $926 \mathrm{mg} / \mathrm{g}\left(25^{\circ} \mathrm{C}\right)$ or $1197 \mathrm{mg} / \mathrm{g}\left(60^{\circ} \mathrm{C}\right)$. The nanocages could be regenerated through the solvothermal method using methanol and treated at $80^{\circ} \mathrm{C}$ over the course of $12 \mathrm{~h}$. Continuous use of the adsorbent demonstrated that there was a slight but continuous loss of the adsorptive capacity for up to five cycles.

The cyclomatrix phosphazenes-co-3,3'-sulfonyldianiline $\mathrm{PSD}^{\prime} \mathrm{NH}_{2}$ microspheres were used to remove methyl orange from solutions [30]. As it was usual in this type of investigation, several variables were considered in the study including: $\mathrm{pH}$, adsorbent dosage, contact time, initial dye concentration, and temperature. The experimental data indicated that the adsorption capacity of the microspheres was $187 \mathrm{mg} / \mathrm{g}$ under the optimal adsorption conditions and followed the pseudo-second-order kinetic and Langmuir isotherm models. Congo red was adsorbed due to (i) intermolecular electrostatic interaction; (ii) hydrogen bonding between the microspheres adsorbed on the surface and the dye; and (iii) $\pi-\pi$ and $\mathrm{C}-\mathrm{H} \ldots \pi$ stacking, in addition to other molecular forces. Dye uptake was endothermic and spontaneous in nature. Desorption data were not included in this work.

Attapulgite modified with 3-aminopropyltriethoxysilane was used in the adsorption of Congo red from waters [31]. It was described that the pseudo-second-order equation and Sips model best-fitted the experimental data. Contrary to the attapulgite behavior, the adsorption via the modified attapulgite was affected neither by the increase of the temperature, nor by the change in the $\mathrm{pH}$ value. Desorption was not considered here. 


\section{Adsorbents for the Removal of Cationic Dyes from Waters}

Novel magnetic $\mathrm{MgFe}_{2} \mathrm{O}_{4} /$ crumbled reduced GO nanoparticles with a surface area of $35 \mathrm{~m}^{2} / \mathrm{g}$ and adsorption capacity near $25 \mathrm{mg} / \mathrm{g}$ were used to eliminate methylene blue (MB) from solutions [32]. In the investigation, several experimental variables were considered: adsorbent dose, dye concentration, $\mathrm{pH}$, rate of agitation, and the change in temperature. The elimination of the dye followed a pseudo-second-order reaction, expressed as

$$
\frac{\mathrm{t}}{[\mathrm{MB}]_{\mathrm{ad}, \mathrm{t}}}=\frac{1}{\mathrm{~K}_{\mathrm{p} 2}[\mathrm{MB}]_{\mathrm{ad}, \mathrm{e}}^{2}}+\frac{\mathrm{t}}{[\mathrm{MB}]_{\mathrm{ad}, \mathrm{e}}}
$$

And characterized by multi-layer formation on the solid surface. In the above equation, $[\mathrm{MB}]_{\mathrm{ad}, \mathrm{e}}$ and $[\mathrm{MB}]_{\mathrm{ad}, \mathrm{e}}$ are the dye concentrations in the adsorbent at the equilibrium and at an elapsed time, respectively; $K_{\mathrm{p} 2}$ is the rate constant; and $t$ is the elapsed time. The values of the enthalpy (endothermic process) and entropy change $(219 \mathrm{~J} / \mathrm{mol} \mathrm{K})$ indicated a strong interaction between the dye molecules and adsorbent surface, as well as an increase of the random arrangement between the organic dye and solid surface. The $10^{-3} \mathrm{M} \mathrm{NaOH}$ solution was used as the desorbent. This magnetic separable adsorbent retained $75 \%$ of its initial adsorption capacity after four consecutive cycles.

A super-adsorbent nanocomposite hydrogel adsorbent was prepared by employing vinyl hybrid silica nanoparticles as a cross-linking agent [33]. This adsorbent presented a remarkable adsorption capacity $(1690 \mathrm{mg} / \mathrm{g})$ towards methylene blue, with a high removal ratio $(90 \%)$ within $40 \mathrm{~min}$. To recover the dye from the loaded adsorbent, $0.1 \mathrm{M} \mathrm{HCl}$ solution was used. After five cycles, there was a continuous decrease from $899 \mathrm{mg} / \mathrm{g}$ to $757 \mathrm{mg} / \mathrm{g}$ in the adsorption capacity.

Used as precursors, $1 \mathrm{D}\left[\mathrm{Mo}_{3} \mathrm{O}_{10}\right]_{\mathrm{n}}{ }^{2 \mathrm{n}-}$ chains and the flexible $\mathrm{N}, \mathrm{N}^{\prime}$-bis(5-methyl-2pyrazinecarboxamide)-1,2-ethane (bmpae), a 3D metal-organic framework ([Cu(bmpae) 0.5 $\left.\left.\left(\mathrm{Mo}_{3} \mathrm{O}_{10}\right)\left(\mathrm{H}_{2} \mathrm{O}\right)\right] \cdot \mathrm{H}_{2} \mathrm{O}\right)$, had been hydrothermally synthesized [34]. Its adsorption capacities towards gentian violet and methylene blue were investigated. It was mentioned in the manuscript that acetonitrile was used in the desorption step.

The superparamagnetic Mn-metal organic framework (MOF) with core-shell nanostructures, synthesized in situ, was developed as a magnetic adsorbent for malachite green removal from aqueous solutions [35]. Three variables were investigated: $\mathrm{pH}$, contact time, and agitation speed. The results showed that the $\mathrm{CoFe}_{2} \mathrm{O}_{4} @ \mathrm{Mn}-\mathrm{MOF}$ core-shell removes about $98 \%$ of the dye from a water medium. This reference seemed to be a rare exception amongst the many published adsorption studies in which the agitation speed was considered an experimental variable to investigate. The effect of this variable on malachite green adsorption was investigated in the $100-400 \mathrm{~min}^{-1}$ range and the results showed that maximum adsorption $(99 \%)$ was reached at $200 \mathrm{~min}^{-1}$; this result was attributable to the decrease of the film boundary layer that wrapped particles and thus adsorption increased. No desorption data were included in the investigation.

It was reported [36] that the preparation of carboxylic acid-modified polysilsesquioxane aerogels via a straightforward acid-base catalyzed the sol-gel approach by using methyltrimethoxysilane (MTMS) and the novel and stable 5-(trimethoxysilyl)pentanoic acid. Besides the adsorption of heavy metals (zinc(II) and copper(II)), the adsorbent was used in the removal of methylene blue and rhodamine B. Experimental data fitted well with the Langmuir isotherm, with the maximum adsorption capacities of $154 \mathrm{mg} / \mathrm{g}$ (rhodamine B) and $106 \mathrm{mg} / \mathrm{g}$ (methylene blue). An increasing content of carboxylic acid groups influenced the morphology, specific surface area, and adsorption behavior of the synthesized aerogels. Desorption was investigated in the case of methylene blue; loaded dye onto the adsorbent was desorbed using $\mathrm{HCl}$ solutions of $\mathrm{pH} \mathrm{1-2} \mathrm{for} 24 \mathrm{~h}$. Under continuous use, the adsorption efficiency was near $92 \%$ for the three first cycles but decreased from the fourth cycle, whereas desorption maintained at an $87 \%$ for the fourth and fifth cycles. These carboxylic acid-modified aerogels only removed positively charged molecules from mixed-dye solutions. 
Hollow polydopamine microcapsules (H-PDA-MCs), synthesized by an oxidation self-polymerization of dopamine using iron trioxide $\left(\mathrm{Fe}_{2} \mathrm{O}_{3}\right)$ nanocubes, were used to adsorb cationic dyes such as methylene blue [37]. The results showed that when near $25^{\circ} \mathrm{C}$, the maximum adsorption capacity was $192 \mathrm{mg} / \mathrm{g}$, with the equilibrium reached within $1 \mathrm{~h}$. The data fitted to the pseudo-second-order kinetic model, the Langmuir model and the Temkin isotherm:

$$
[\mathrm{MB}]_{\mathrm{ad}, \mathrm{e}}=\mathrm{B}_{1} \ln \mathrm{K}_{\mathrm{t}}+\mathrm{B}_{1} \ln [\mathrm{MB}]_{\mathrm{aq}, \mathrm{e}}
$$

where $B_{1}$ represents the Temkin constant associated with the adsorption heat and $\mathrm{K}_{\mathrm{T}}$ was the equilibrium binding constant. The increase of the temperature increased the dye uptake onto the adsorbent (Table 3 ) and thus the adsorption was an endothermic and spontaneous process. In this system, desorption was performed with $1 \mathrm{M}$ of $\mathrm{HCl}$ solution and sonication for $60 \mathrm{~min}$, and after a post-treatment the adsorbent was reused.

Table 3. Effect of temperature on the theoretical maximum adsorption capacity.

\begin{tabular}{cc}
\hline Temperature, $^{\circ} \mathbf{C}$ & {$[\mathbf{M B}]_{\mathbf{a d}, \mathbf{m}, \mathbf{m g} / \mathbf{g}}$} \\
\hline 20 & 228 \\
25 & 233 \\
30 & 237 \\
\hline Abbreviation: MB, methylene blue.
\end{tabular}

Hierarchical microspheres of $\mathrm{ZnOHF}$ were produced using DL-alanine as the structuredirecting agent [38]. These microspheres were formed by numerous nanotubes and were used in the adsorption of organic dyes, though the adsorption of cationic dyes was favored with respect to neutral or anionic dyes. Adsorption data fitted to the Langmuir isotherm and pseudo-second-order kinetic model. The maximum adsorption capacity of the microspheres was $140 \mathrm{mg} / \mathrm{g}$ for malachite green at $25{ }^{\circ} \mathrm{C}$ in an endothermic and spontaneous physical adsorption process. After five cycles, adsorption decreased from $100 \%$ to $75 \%$, though it was not indicated if the dye was desorbed or the adsorbent was used without desorption.

Mesoporous silica derived from iron ore tailings was synthesized [39] and used in the adsorption of methylene blue. The removal of the dye ( $\mathrm{pH} 10)$ responded to the Langmuir isotherm and pseudo-second-order equation, and thus to a monolayer adsorption, with the adsorption capacity of $192 \mathrm{mg} / \mathrm{g}$. The desorption step was not considered here.

Methylene blue and basic violet 16 dyes were removed from an aqueous solution using sulfonated poly(ether ether ketone) (sPEEK) [40]. Kinetic experiments revealed that in the case of both dyes, data were well-fitted by the pseudo-second-order kinetic model, whereas the required times to achieve equilibrium were determined as 40 and 20 min for methylene blue and basic violet 16, respectively. Maximum adsorptions occurred at the $\mathrm{pH}$ of 3-6 (methylene blue) and 3 (basic violet 16). The adsorptions responded to the Langmuir model and the maximum adsorption capacities were found to be $98 \mathrm{mg} / \mathrm{g}$ (methylene blue) and $182 \mathrm{mg} / \mathrm{g}$ (basic violet 16). In the case of methylene blue, the adsorption process presented an endothermic and spontaneous character. This dye was desorbed using $3 \mathrm{M}$ nitric acid/ethanol (30/70\% v/v) mixtures for $20 \mathrm{~min}$ and recycling experiments on methylene blue showed that the adsorption efficiency decreased from $99.6 \%$ to $99.2 \%$ after five cycles, whereas low desorption percentage values of basic violet 16 indicated that this adsorbent may be used for immobilizing the dye.

A natural adsorbent of graham flour was selected as an adsorbent to remove cationic crystal violet from water [41]. The effective $\mathrm{pH}$ range for dye adsorption was in the neutral $\mathrm{pH}$ region, following the Langmuir isotherm, with the maximum adsorption capacity of $162 \mathrm{mg} / \mathrm{g}$. The polymeric GF adsorbent was selective respect to crystal violet from the synthetic polluted sample, even in the presence of a high concentration of diverse competing ions. The adsorbed dye could be desorbed with ethanol, with a continuous decrease in its capacity observed for up to seventh cycles. 
The next reference deals with the encapsulation of methylene blue on the polymeric natural carbohydrate of the turmeric powder adsorbent [42]. The maximum dye removal of $99.5 \%$ was obtained at $\mathrm{pH} 7$. In the acidic $\mathrm{pH}$ region, the positively charged protonated adsorbent did not favor the adsorption of positively charged protonated methylene blue due to electrostatic repulsion. In the neutral $\mathrm{pH}$ area, the removal of the dye from the solution was explained by electrostatic attraction and complexation of the dye with the adsorbent. The adsorption data were fitted to the Langmuir isotherm, with a maximum adsorption capacity of $157 \mathrm{mg} / \mathrm{g}$. Ethanol can be used to desorb the dye from the adsorbent; its original capacities were reduced for up to seventh cycles.

Sulfonic acid-functionalized carbon nanotubes' (CNT-FA-SA) composite was synthesized by Diels-Alder (DA) chemistry and the electrophilic substitution reaction [43], and the adsorption of methylene blue onto CNT-FA-SA was investigated. The loading capacity, in an exothermic adsorption process, increased with the increase of the $\mathrm{pH}$ from 2 to 12. The non-linear fitting of the data to Freundlich or Langmuir isotherm models estimated that the maximum adsorption capacity of the monolayer was $1584 \mathrm{mg} / \mathrm{g}$. The adsorption kinetic responded to the non-linear form of the pseudo-second-order equation. The data indicated that the adsorption process was related to chemisorption and physical adsorption simultaneously, and that the adsorption occurred on a heterogeneous multilayer surface. No desorption data were included in the manuscript.

A trichlorotriazine-derived calix[4] arene and 1,3,5-tris(4-aminophenyl) benzene were cross-linked to produce a calix[4]arene cross-linked polymer with adsorptive properties towards cationic dyes from water [44]. This polymer showed the removal efficiency as over $99.6 \%$ and $99.4 \%$ for methylene blue and toluidine blue within 5 min, respectively, and Table 4 presents some of the equilibrium capacities obtained with this adsorbent. In the case of methylene blue and toluidine B, the adsorption followed the pseudo-secondorder model and the Langmuir isotherm. Maximum equilibrium adsorption capacities for methylene blue and toluidine blue were 1807 and $2161 \mathrm{mg} / \mathrm{g}$, respectively. These results were attributable to electrostatic interactions, $\pi-\pi$ interactions, and the hydrogen bonding between the polymer and organic dyes. In column experiments, the removal of the above dyes was of $99 \%$, except in the case of sodium fluorescein which reached $80 \%$. Desorption was investigated in the column operation and by using methanol as a desorbent; after five cycles, the removal efficiency was greater than $95 \%$.

Table 4. Equilibrium capacities of the adsorbent.

\begin{tabular}{cccc}
\hline Dye & {$\left[\right.$ Dye $_{\mathbf{a d}, \mathbf{e}}, \mathbf{m g} / \mathbf{g}$} & Dye & {$[\text { Dye }]_{\mathbf{a d}, \mathbf{e}}, \mathbf{m g} / \mathbf{g}$} \\
\hline Methylene blue & 252 & Crystal violet & 1.6 \\
Toluidine B & 226 & Rhodamine B & 2 \\
Methyl orange & 47 & Sodium fluorescein & 4.2 \\
\hline
\end{tabular}

pH 10. Time: $30 \mathrm{~min}$.

A hexatungstate derivative, $\left[\mathrm{Ni}_{2}(\mathrm{~L})_{3}\right]_{2}\left[\mathrm{~W}_{6} \mathrm{O}_{19}\right] \cdot 2 \mathrm{H}_{2} \mathrm{O}(\mathrm{HL}$ : 2-acetylpyrazine- $\mathrm{N}(4)$ methyl thiosemicarbazone), has been synthesized, characterized, and used in the adsorption of methylene blue, gentian violet, and fuchsin basic [45], with removal efficiencies of $99 \%, 94 \%$, and $94 \%$, respectively. The different reactivity over the various dyes was caused by the electrostatic interactions between the dyes and the $\left[\mathrm{W}_{6} \mathrm{O}_{19}\right]^{2-}$ molecules. Methylene blue uptake onto the adsorbent followed the pseudo-second-order kinetic equation. After five cycles of adsorption-desorption, the capacity decreased from $99 \%$ to $82 \%$, this decrease attributable to the loss of adsorbent during each washing step.

Rice husk ash can be used as a sustainable source of silica for producing high valuable subproducts. This product served as a precursor for mesostructural graphene oxide and was used to adsorb methylene blue from solutions via oxygen functional groups presented in the adsorbent [46]. The adsorption capacity depended on the gelation $\mathrm{pH}$, graphene oxide content, adsorbent dosage, and initial dye concentration. The highest adsorption capacity was $633 \mathrm{mg} / \mathrm{g}$ and the data fitted to the Freundlich or Langmuir models depending 
of the type of adsorbent material used in the investigation. In all the cases, the data fitted to the pseudo-second-order kinetic model. Desorption information was not included in the manuscript.

HKUST-1/cellulose/chitosan aerogel composite with hierarchical pores was investigated to remove methylene blue [47]. With a high adsorption capacity $(526 \mathrm{mg} / \mathrm{g})$, the removal of the dye increased from $\mathrm{pH} 3$ to 7 , with levels off until $\mathrm{pH} 8$ and then decreasing from $\mathrm{pH} 9$ to 11. It was determined that the adsorption occurred through H-bond interactions between oxygen and nitrogen atoms in the composite aerogel and nitrogen atoms from the organic dye. The adsorption fitted to the pseudo-first and pseudo-second-order models, and thus the adsorption was due to a synergistic effect of chemical and physical mechanisms. Desorption was investigated using ethanol and water under lyophilization. After five cycles, the adsorption capacity decreased from $162 \mathrm{mg} / \mathrm{g}$ to $153 \mathrm{mg} / \mathrm{g}$.

The adsorption behavior of different adsorbents has been studied by various research works but few studies have compared linear and non-linear isotherm and kinetic models alongside phenomenological coefficients. The effect of activated carbon black on methylene blue adsorption behavior of alginate was examined [48]. A low-cost and green adsorbent was fabricated to easily detach from water. The results were well-fitted with non-linear pseudo-second-order and linear Langmuir models. The intraparticle diffusion model and phenomenological coefficients represented the control of adsorption by film diffusion and its limiting by pore diffusion. No desorption data were included in this work.

A graphitic carbon nitride was developed to decrease the contamination produced by diverse compounds, including dyes [49]. The investigation was focused on the removal of methylene blue from aqueous solutions. The dye was removed from the solution very quickly, in a matter of seconds, without any additional physical or chemical activation. No desorption data were included in this work.

The next investigation showed the abilities of F-terminated $\mathrm{Ti}_{3} \mathrm{C}_{2} \mathrm{~T}_{\mathrm{x}}-\mathrm{MXene}$ as an adsorbent of methylene blue-bearing wastewater [50]. The adsorption efficiency towards this dye sharply decreased from $\mathrm{pH} 4$ to $\mathrm{pH} 7$, with maximum adsorption achieved at $\mathrm{pH} 2$. The adsorption was based on the following reactions:

$$
\begin{gathered}
{[\mathrm{Ti}-\mathrm{F}]^{-}+\mathrm{MB}^{+}=\mathrm{Ti}-\mathrm{F}-\mathrm{MB}} \\
{[\mathrm{Ti}-\mathrm{O}]^{-} \mathrm{H}^{+}=[\mathrm{Ti}-\mathrm{O}]^{-}+\mathrm{H}^{+}} \\
{[\mathrm{Ti}-\mathrm{O}]^{-}+\mathrm{MB}^{+}=\mathrm{Ti}-\mathrm{O}-\mathrm{MB}}
\end{gathered}
$$

Thus, $\mathrm{F}$ and $\mathrm{O}$ terminations attracted methylene blue (MB) molecules. Other dyes (methyl orange and rhodamine B) could be also adsorbed, though the adsorption was dependent on the exposure time, increasing with the time in the case of the above dyes. The removal efficiency of methylene blue slightly decreased from the first to the fourth cycle.

A material formed by polystyrene sulfonate on a laterite soil was investigated to adsorb crystal violet and methylene blue from an aqueous solution [51]. Both dyes were effectively removed from the solution after $75 \mathrm{~min}$ at $\mathrm{pH}$ values of 8 (crystal violet) or 9 (methylene blue). In addition, in both cases, the adsorption efficiency increased from $\mathrm{pH} 2$ to alkaline values. The adsorption data derived from both dyes indicated exothermic and spontaneous adsorption processes, and fitted-well to the Langmuir model, with the capacity in a solution of ionic strength $1 \mathrm{mM}$ of about $43 \mathrm{mg} / \mathrm{g}$ (crystal violet) and $14 \mathrm{mg} / \mathrm{g}$ (methylene blue). Desorption data were absent in the investigation.

A natural bentonite was used as an adsorbent to remove basic red 46 from an aqueous solution [52]. Throughout the experimentation, an adsorbent concentration of $0.1 \mathrm{~g} / \mathrm{L}$ was used. At pH 7 and $25^{\circ} \mathrm{C}$, the maximum adsorption capacity was $594 \mathrm{mg} / \mathrm{g}$, with the experimental data best-fitted to the Langmuir isotherm and pseudo-second-order kinetic model. The increase of the temperature was associated to a decrease of dye uptake onto the adsorbent. Investigations about the desorption step were not included in this work.

As it was mentioned above, pristine carbon materials tended to have a low dyeremoval capacity. One method to improve this fault was to tune the carbonaceous material 
with a complementary one. One type of material that could be added was biomaterials. In the next reference, a sulfur-tethered adsorbent of the chitosan-tapioca peel biochar composite was fabricated. The peel of tapioca acted as a precursor for the fabrication of the biochar matrix. The removal of malachite green and rhodamine $B$ from solutions using this adsorbent was investigated [53]. Using dye concentrations of $50 \mathrm{mg} / \mathrm{L}$, the uptakes were $53 \mathrm{mg} / \mathrm{g}$ (malachite green) and $41 \mathrm{mg} / \mathrm{g}$ (rhodamine B) at a pH near 8 and after $120 \mathrm{~min}$. The adsorption followed the pseudo-second-order kinetics and Langmuir isotherm equations. As the norm, dye adsorption was attributable to (i) electrostatic attractions, (ii) hydrogen bonding, and (iii) $\pi-\pi$ interactions. Using $0.1 \mathrm{M}$ of $\mathrm{NaOH}$ solutions to desorb the loaded dyes, the adsorbent was used in five successive cycles of adsorption-desorption with a continuous decrease in its properties to remove the dyes from the solution.

In a very similar investigation to the one above [54], the same adsorbent and dyes were used, though in this case [53], the dyes' concentrations were $25 \mathrm{mg} / \mathrm{L}$ because the uptake was lower than in the previous reference, namely $30 \mathrm{mg} / \mathrm{L}$ versus $53 \mathrm{mg} / \mathrm{g}$ (malachite green) or $33 \mathrm{mg} / \mathrm{g}$ versus $41 \mathrm{mg} / \mathrm{g}$ (rhodamine B). Additionally, the best uptakes were yielded at a $\mathrm{pH}$ near 8 and after $120 \mathrm{~min}$ of reaction. The experimental data also followed the pseudo-second-order kinetic model, but in this case, the adsorption fitted to the Freundlich isotherm instead of the Langmuir isotherm. The adsorbent also lost its properties under the five cycles of adsorption-desorption.

$\mathrm{Zn}_{3}(\mathrm{OH})_{2} \mathrm{~V}_{2} \mathrm{O}_{7} \cdot 2 \mathrm{H}_{2} \mathrm{O}$ nanocables have been fabricated by a DL-Alanine-assisted hydrothermal route and were used in the adsorption of methylene blue [55]. The maximum adsorption capacity was $113 \mathrm{mg} / \mathrm{g}$ at $25^{\circ} \mathrm{C}$ in a physisorption process, following the pseudo-second-order equation and Langmuir isotherm. No desorption data were included in this work.

A mixed process of biomodification and magnetic treatment was used to prepare polydopamine-modified graphene-based adsorbents, which incorporated active $\mathrm{Fe}_{3} \mathrm{O}_{4}$ nanoparticles (average size of $6.5 \mathrm{~nm}$ ) [56]. With an increase of the adsorption capacity from $\mathrm{pH} 2$ to 10, the adsorption equilibrium was reached after $7 \mathrm{~h}$. The adsorption of methylene blue followed the pseudo-second-order kinetic model, the intraparticle diffusion model, and the Langmuir isotherm. Maximum adsorption capacities were $132 \mathrm{mg} / \mathrm{g}\left(30^{\circ} \mathrm{C}\right)$, $140 \mathrm{mg} / \mathrm{g}\left(40^{\circ} \mathrm{C}\right)$, and $152 \mathrm{mg} / \mathrm{g}\left(50^{\circ} \mathrm{C}\right)$, with the adsorption presented as endothermic and spontaneous. It also showed an increase in the randomness at the solid-solution interface. Desorption followed an acid treatment to induce the dye removal from the adsorbent, this caused by the generation of an excess of protons which competed with the cationic dye and endowed the amine groups of the adsorbent with a positive charge with the subsequent repulsion of the dye molecule. After five cycles, the adsorbent showed a continuous decrease of its initial removal rate.

Another adsorbent-based metal-organic framework with nanometer blocks of amidefunctionalized $\mathrm{Fe}(\mathrm{III})$-based metal-organic frameworks were produced via the ultrasonic method and without the addition of any surfactants, at room temperature and with atmospheric pressure [57]. It was used in the removal of methylene blue for the solution. No desorption data were included in this work.

A $\beta$-cyclodextrin/graphene oxide composite was prepared by modifying graphene oxide via the $\beta$-cyclodextrin cross-linking method [58]. The composite was used to investigate its possibilities in the removal of methylene blue from an aqueous solution. Under the optimal conditions of temperature $\left(70^{\circ} \mathrm{C}\right)$, time $(60 \mathrm{~min})$, and adsorbent dosage $(0.04 \mathrm{~g} / \mathrm{L})$, and at $\mathrm{pH} 7$, a removal efficiency of $90 \%$ was achieved, which compared better than that of the graphene oxide $(70 \%)$. The maximum adsorption capacity was $76 \mathrm{mg} / \mathrm{g}$ and the dye was removed from the adsorbent by desorption with absolute alcohol during $12 \mathrm{~h}$. Removal efficiency was maintained at about $90 \%$ after nine cycles.

As physalis alkekengi L. husk is an agricultural waste product, its disposal causes environmental pollution of water and air. Thus, in order to give a further utility to this waste, it was used as precursor of a porous carbon material. Malachite green (MG) was 
used to investigate the adsorption properties of the material [59]. It was found that at a $\mathrm{pH}$ of 9 , the maximum adsorption capacity of the adsorbent reached near $2000 \mathrm{mg} / \mathrm{g}$, whereas $51 \%(1016 \mathrm{mg} / \mathrm{g})$ of the dye was adsorbed in the first $5 \mathrm{~min}$. Dye uptake followed the pseudo-second-order and Banghman models

$$
[\mathrm{MG}]_{\mathrm{ad}, \mathrm{t}}=[\mathrm{MG}]_{\mathrm{ad}, \mathrm{e}}\left(1-\mathrm{e}^{-\mathrm{K}_{4} \mathrm{t}^{\mathrm{n}}}\right)
$$

where $\mathrm{K}_{4}$ represents the Bangham rate constant and $\mathrm{n}$ represents the power of the Bangham model. The increase of the temperature in the $20-40{ }^{\circ} \mathrm{C}$ range produced a slight increase in the adsorption capacity, which followed the Langmuir model. Deionized water was used to desorb the dye and the adsorbent was recarbonized at $600{ }^{\circ} \mathrm{C}$ under nitrogen atmosphere. After ten cycles, the adsorbent decreased its removal rate from $100 \%$ to $89 \%$, though further recycling caused a slight decrease in the adsorption capacity, probably caused by the deposition of the byproducts on the adsorbent surface.

\section{Adsorbents for the Removal of Anionic and Cationic Dyes from Waters}

A magnetic metal-organic framework adsorbent $\left(\mathrm{Fe}_{3} \mathrm{O}_{4} @ \mathrm{UiO}-66\right)$, based on functionalized magnetic $\mathrm{Fe}_{3} \mathrm{O}_{4}$ nanoparticles and highly water-stable UiO-66, was used to remove methyl orange and methylene blue from aqueous solutions [60]. In the case of methylene blue, the adsorption data fitted well to the linearized Freundlich model:

$$
\ln [\mathrm{MB}]_{\mathrm{ad}, \mathrm{e}}=\ln \mathrm{K}_{\mathrm{F}}+\frac{1}{\mathrm{n}} \ln [\mathrm{MB}]_{\mathrm{aq}, \mathrm{e}}
$$

where $K_{F}$ represents the constant model, $[\mathrm{MB}]_{\mathrm{aq}, \mathrm{e}}$ represents the methylene blue concentration in the solution at the equilibrium, and $n_{F}$ represents a value which indicates whether the process is favorable ( $n_{F}$ greater than one) or not. The experimental data derived from the adsorption of methyl orange (MO) indicated that the linearized form of the Langmuir isotherm was the best fit.

$$
\frac{[\mathrm{MO}]_{\mathrm{aq}, \mathrm{e}}}{[\mathrm{MO}]_{\mathrm{ad}, \mathrm{e}}}=\frac{1}{\mathrm{~K}_{\mathrm{L}}[\mathrm{MO}]_{\mathrm{ad}, \mathrm{m}}}+\frac{1}{[\mathrm{MO}]_{\mathrm{ad}, \mathrm{m}}}[\mathrm{MO}]_{\mathrm{aq}, \mathrm{e}}
$$

In this equation, $\mathrm{K}_{\mathrm{L}}$ represents the model constant and the subscript ad,m represents the maximum dye concentration in the adsorbent. This adsorbent had adsorption uptakes of $244 \mathrm{mg} / \mathrm{g}$ and $205 \mathrm{mg} / \mathrm{g}$ for methyl orange and methylene blue, respectively. The adsorption kinetic experiments demonstrated that the adsorption data for both dyes well-fitted the pseudo-second-order model. The thermodynamic data indicated that the adsorption of both dyes onto the adsorbent was spontaneous and presented an endothermic character. To release the dyes loaded onto the adsorbent, water and ethanol under ultrasonic treatment were used. After eight cycles, there was a continuous decrease in the adsorption capacity of both dyes onto the adsorbent.

Two Zr-based metal-organic cages, namely Zr-MOC-1 (tetrahedral structure) and ZrMOC-2 (capsule-like cage skeleton), were synthesized under solvothermal conditions [61]. The adsorption performances of Zr-MOCs for the organic dyes (methylene blue, crystal violet, methyl orange, and orange $G$ ) from aqueous solutions were reported. The desorption step using ethanol was only mentioned in the case of methylene blue.

An iron-based Fe-BTC MOF, prepared according to an aqueous-based procedure, was used as an adsorbent for the removal of alizarin red $S$ and malachite green from aqueous phases [62]. Optimal adsorption was reached at $\mathrm{pH} 4$ due to the favorable interactions between the dyes and the adsorbent. The kinetic investigation concluded that for the two investigated dyes, the pseudo-second-order model was followed. Accordingly with the Langmuir model, maximum adsorption capacities of $80 \mathrm{mg} / \mathrm{g}$ and $177 \mathrm{mg} / \mathrm{g}$ were found for alizarin red $S$ and malachite green, respectively. No desorption data were included in the published manuscript. 
The solvothermal self-assembly between $\mathrm{Cd}^{2+}$ and a hexacarboxylic acid created the porous material formulae as $\left[\left(\mathrm{CH}_{3}\right)_{2} \mathrm{NH}_{2}\right]_{6}\left[\mathrm{Cd}_{3}(\mathrm{~L})_{2}\right] \cdot 5 \mathrm{DMF} \cdot 3 \mathrm{H}_{2} \mathrm{O}\left(\mathrm{H}_{6} \mathrm{~L}\right.$ responded to 3,4di(3,5-dicarboxyphenyl)phthalic acid), which selectively adsorbed cationic dyes against neutral or anionic compounds [63]. The investigation was based on the adsorption of azure A+ and methylene blue+, with adsorption capacities of $698 \mathrm{mg} / \mathrm{g}$ (azure A+) and $573 \mathrm{mg} / \mathrm{g}$ (methylene blue + ). As acetonitrile cannot desorb the dye, desorption was performed using a NaCl-acetonitrile solution and the mission of $\mathrm{Na}^{+}$ions was to displace the dye cation to conserve the stability of the adsorbent skeleton and charge balance. After five cycles, both adsorption and desorption capacities slightly but continuously decreased.

A carboxyl-functionalized covalent organic framework (TpPa-COOH) was synthesized under environmental pressure and the adsorptive properties were investigated using eosin B (anionic dye) as well as the cationic dyes methylene blue and safranine T [64]. TpPa$\mathrm{COOH}$ showed a selective adsorption effect on the two cationic dyes. In these two cases, the adsorption isotherm responded to the Langmuir model, with maximum capacities of $1135 \mathrm{mg} / \mathrm{g}$ (safranine T) and $410 \mathrm{mg} / \mathrm{g}$ (methylene blue). The desorption step was only investigated in the case of safranine $\mathrm{T}$ and the step was carried out with tetrahidrofurane and $1 \mathrm{M} \mathrm{HCl}$; the lean adsorbent was washed with ethanol and dried under vacuum at $60{ }^{\circ} \mathrm{C}$ over the course of $12 \mathrm{~h}$. After three cycles, the removal efficiency decreased from $99 \%$ to $95 \%$.

Magnetic chitosan hydrogel beads, based on chitosan biopolymer, magnetic graphene oxide nanoparticles $\left(\mathrm{GO} / \mathrm{Fe}_{3} \mathrm{O}_{4}\right)$, and isophthaloyl chloride, were prepared and used in the removal of cationic and anionic dyes from an aqueous solution [65]. Experimental results showed that data were best-fitted to the pseudo-second-order kinetic model and non-linear Langmuir isotherm. The maximum adsorption capacities of methylene blue and eriochrome black T were $289(\mathrm{pH} 8-10)$ and $292(\mathrm{pH} 3) \mathrm{mg} / \mathrm{g}$, respectively. The removal of the dyes from the solution was associated to an endothermic, spontaneous, and favorable process, as the $\mathrm{R}_{\mathrm{L}}$ values derived from:

$$
\mathrm{R}_{\mathrm{L}}=\frac{1}{1+\mathrm{K}_{\mathrm{L}}[\text { dye }]_{\mathrm{aq}, 0}}
$$

In which 0.012 (methylene blue) and 0.010 (eriochrome black T) are included. In the above equation, $\mathrm{K}_{\mathrm{L}}$ represents the Langmuir constant estimated by the corresponding fit and $[\text { dye }]_{\text {aq, }}$ represents the initial dye concentration in the aqueous solution. Dye uptake was attributed to the electrostatic interactions of the dyes with the primary amine and hydroxyl and carboxyl groups of the adsorbent beads. Desorption was performed using $\mathrm{HCl}(\mathrm{pH} 3)$ in the case of methylene blue or $\mathrm{NaOH}(\mathrm{pH} 9)$ in the case of eriochrome black T. The adsorption-desorption properties were well-maintained for up to four cycles but from the fifth cycle, they began to decrease.

A boron-doped mesoporous carbon material was generated from F127 (block polyether $\left.\left(\mathrm{EO}_{106}-\mathrm{PO}_{70}-\mathrm{EO}_{106}\right)\right)$ as a soft template and both phenolic resin and triisopropyl borate were selected as the carbon and boron-containing precursors [66]. The prepared material had been used in the adsorption of crystal violet and Congo red dyes. In both cases, the experimental data fitted the Langmuir isotherm and the pseudo-second kinetic equation, with dye uptakes of $385 \mathrm{mg} / \mathrm{g}$ (crystal violet) or $323 \mathrm{mg} / \mathrm{g}$ (Congo red). After five rounds of circulation, the removal rate decreased from $79 \%$ to $63 \%$ (Congo red) and $94 \%$ to $80 \%$ (crystal violet); this decrease may be caused by the disappearance or weakening of the vacancy sites on the adsorbent in the desorption process. In the published manuscript, how the desorption procedure was carried out was not clearly mentioned.

The adsorption performance of delaminated $\mathrm{Ti}_{3} \mathrm{C}_{2}$-MXenes towards six different organic dyes in aquatic media at different $\mathrm{pH}$ levels and ionic strengths was investigated [67]. The ability of this adsorbent to remove the dyes was based on the electrostatic interactions between the ionizable functional groups of MXenes and the dyes. The $\mathrm{pH}$ had a different influence on the dye adsorption and in the case of methylene blue, the adsorption of this dye increased with the $\mathrm{pH}$ value from 2 to 10 . Methyl orange presented an increase in 
its adsorption from $\mathrm{pH} 2$ to 4 , with a further stabilization until $\mathrm{pH} 10$. The removal of Congo red was stable in the $2-10 \mathrm{pH}$ range and then decreased until $\mathrm{pH} 12$. Methyl red was adsorbed in the range of 2-4 with a sharp decrease up to $\mathrm{pH} 10$ (negligible adsorption). Lastly, in the case of orange $\mathrm{G}$, a $60 \%$ adsorption rate was achieved at $\mathrm{pH} 2$ and near zero at $\mathrm{pH} 4$. In water, methyl red (MR) adsorption was attributable to the intraparticle diffusion model:

$$
[\mathrm{MR}]_{\mathrm{ad}, \mathrm{t}}=\mathrm{K}_{\mathrm{p}} \mathrm{t}^{0.5}+[\mathrm{MR}]_{\mathrm{ad}, \mathrm{t}=0}
$$

where $K_{p}$ represents the rate constant. In all the other dyes, the fitting of the results was not clear. No desorption data were included in this work.

Highly dispersed graphene nanosheets were directly integrated into a polyurethane sponge and the resulting material was used as an adsorbent towards methylene blue, ethidium bromide, and eosin Y [68]. The dye uptake followed the Langmuir isotherm model, which provided evidence of a strong monolayer chemisorption. In the three cases, the adsorption process was spontaneous and exothermic, and the dye uptake fitted to the pseudo-second-order kinetic model. In the case of the cationic dyes, the adsorption increased with the increase of the $\mathrm{pH}$, e.g., the maximum adsorption capacity at $\mathrm{pH} 10$ within methylene blue and ethidium bromide, whereas anionic dyes followed the opposite tendency, e.g., $\mathrm{pH} 3$ for eosin Y. Again, desorption data were absent in this work.

An aerogel formed by graphene-polydopamine-bovine serum albumin, to which biopolymers were added, was used in the removal of organic dyes (methylene blue and Evans blue), toxic metals ( $\mathrm{Cr}(\mathrm{VI})$ and $\mathrm{Pb}(\mathrm{II})$ ), and organic solvents (n-hexane,n-heptane and toluene) [69]. In the case of both organic dyes, the adsorption capacity increased when the $\mathrm{pH}$ value increased from 2 to 8 . Desorption was only investigated in the case of methylene blue using ethanol at $\mathrm{pH} 2$ during $24 \mathrm{~h}$. After three cycles, the removal efficiency for methylene blue decreased by $2-20 \%$ (depending on the dye concentration). The system was used in a continuous form using a flow-through filtration system.

Using zirconium, a Zr-based metal-organic framework was synthesized by a solvothermal procedure. The adsorptive characteristics of such materials were investigated against the presence of methyl red and methylene blue in solutions [70]. Experiments showed that a change in the activation solvent and activation method altered the physical properties of the adsorbent (surface area, pore-volume, pore diameter, and surface charge), and thus the capacity to remove the dyes was also altered. Some of the experimental results are summarized in Table 5.

Table 5. Performance of the adsorbent at various activations and methods of activation.

\begin{tabular}{cccccc}
\hline Adsorbent & Activation & Method & $\begin{array}{c}\text { Days of } \\
\text { Activation }\end{array}$ & $\begin{array}{c}\text { \% MB } \\
\text { Adsorption }\end{array}$ & $\begin{array}{c}\text { \% MR } \\
\text { Adsorption }\end{array}$ \\
\hline AS-5 & Acetone & Soxhlet & 5 & 19 & 93 \\
CS-5 & Chloroform & Soxhlet & 5 & 62 & 82 \\
ES-5 & Ethanol & Soxhlet & 5 & 41 & 95 \\
AC-5 & Acetone & Centrifugation & 5 & 43 & 90 \\
CC-5 & Chloroform & Centrifugation & 5 & 80 & 94 \\
EC-5 & Ethanol & Centrifugation & 5 & 44 & 85 \\
\hline Abbreviations:
\end{tabular}

Abbreviations: MB, methylene blue and MR, methyl red.

The adsorption of methylene blue increased with the increase of the $\mathrm{pH}$ value, with a maximum capacity of $217 \mathrm{mg} / \mathrm{g}$, whereas that of methyl red reached a maximum at $\mathrm{pH} 2(243 \mathrm{mg} / \mathrm{g})$; thus, by controlling the $\mathrm{pH}$ of the solution, the adsorbent can be used to selectively separate one from the another. In both cases, adsorption followed the Langmuir and pseudo-second-order kinetic models, and the adsorption was both spontaneous and endothermic. Desorption used acidic ethanol solutions under ultrasonic assistance over the course of $1 \mathrm{~h}$ as the desorbent procedure. After five cycles, a slight decrease in the adsorption capacity was shown either for methyl red or methylene blue dyes. 
Cobalt ferrite nanoparticles capped with an ultrathin phosphate layer of near $1 \mathrm{~nm}$ thick were synthesized and characterized using usual techniques [71] and they were used in the adsorption of a number of dyes. These capped nanoparticles adsorbed $4.5 \mathrm{mg} / \mathrm{g}$ (89.5\% adsorption) of methylene blue within $5 \mathrm{~min}$, a value which compared well with the practically non-adsorption quality of the dye using the uncoated cobalt ferrite. Using solutions of $50 \mathrm{mg} / \mathrm{L}$ of the corresponding dye, the adsorption efficiency for various dyes included: brilliant blue R (92\%), bromo phenol blue (75\%), and methylene blue $(91 \%)$. No desorption data were included here.

The in-situ growth of zeolitic imidazolate frameworks on zinc-layered doublehydroxide, which developed in a porous composite material (ZIF-8@ZnAl-LDH), was investigated [72]. This material was used in the removal of malachite green and methyl orange from water. In both cases, adsorption equilibrium was reached after $2 \mathrm{~h}$ and it followed the Langmuir isotherm. Due to the nature of these dyes, the $\mathrm{pH}$ influenced their adsorption in contrary manner: an increase of the $\mathrm{pH}$ from 2 to 10 favored the adsorption of malachite green, whereas methyl orange was best removed from the solution at acidic $\mathrm{pH}$ values (e.g., 3). Ethanol was effective in the desorption of both dyes and after four consecutive cycles, the adsorbent maintained a $97 \%$ and $95 \%$ adsorption rate for malachite green and methyl orange, respectively, of its initial adsorption capacity. These results were attributable to the adsorbent characteristics including: (i) greater superficial area, (ii) porous structure, and (iii) exposed metallic nodes within the specific morphological inter-layered structure.

A biosynthesis strategy using $\mathrm{MgO}$ nanoparticles and various Tecoma stans (L.) plant extracts (flower, bark, and leaf) was developed in order to find a suitable adsorbent for organic dyes [73]. The investigated dyes were Congo red and crystal violet, and the variables investigated were $\mathrm{pH}$, time, and dye concentration. The best conditions for Congo red uptake $(99.7 \%)$ were a $\mathrm{pH}$ of 7.9 and concentration of $9.3 \mathrm{mg} / \mathrm{L}$, whereas crystal violet was adsorbed $(90.8 \%)$ at a $\mathrm{pH}$ value of 6.3 and concentration of $5 \mathrm{mg} / \mathrm{L}$. Maximum adsorption capacities were produced when the adsorbent presented when the flower extract was used and it varied from 89 (Congo red) to $150 \mathrm{mg} / \mathrm{g}$ (crystal violet). The adsorption of both dyes followed the Langmuir isotherm and pseudo-second-order kinetic model. Under the continuous use of three cycles, there was a continuous decrease in the effectiveness of both adsorption-desorption operations.

Again using metal-organic frameworks, two mixed compounds, namely $\left\{\left[\mathrm{Zn}_{2}\left(5 \mathrm{NO}_{2}-\right.\right.\right.$ $\left.\left.\mathrm{IP})_{2}(\mathrm{~L})_{2}\right]\left(\mathrm{H}_{2} \mathrm{O}\right)\right\}_{n}$, named ADES- 1 , and $\left\{\left[\mathrm{Cd}_{2}\left(5 \mathrm{NO}_{2}-\mathrm{IP}\right)_{2}(\mathrm{~L})_{2}\left(\mathrm{H}_{2} \mathrm{O}\right)_{4}\right](\mathrm{L})\left(\mathrm{H}_{2} \mathrm{O}\right)\left(\mathrm{CH}_{3} \mathrm{OH}\right)_{6}\right\}_{\mathrm{n}}$, named ADES-2, and where $5 \mathrm{NO}_{2}-\mathrm{IP}=5$-nitroisophthalate and $\mathrm{L}=(\mathrm{E})-\mathrm{N}^{\prime}$-(pyridin-3ylmethylene)nicotinohydrazide), had been synthesized and characterized via normal techniques [74]. ADES-1 allowed for the rapid and efficient adsorption of both cationic and anionic dye molecules, though it showed a preference for methyl violet ( $86 \%$ adsorption) if compared to the other dyes that were investigated; some of these results are summarized in Table 6. The usefulness of ADES- 1 in the separation of a mixture of dyes and its use in a column for the same purpose were also investigated. Desorption was investigated using methanol and $90 \mathrm{~min}$ of reaction time.

Table 6. Adsorption of dyes by ADES-1.

\begin{tabular}{ccc}
\hline Dye & Removal Efficiency, $\%$ & [Dye $_{\text {ad.e, }} \mathbf{~} \mathbf{m g} / \mathbf{g}$ \\
\hline Methyl violet & 86 & 1.8 \\
Methylene blue & 80 & 1.7 \\
Rhodamine B & 60 & 1.3 \\
Methyl orange & 54 & 0.99 \\
\hline
\end{tabular}

Initial dye concentration: $5 \times 10^{-5} \mathrm{M}$. Time: $3 \mathrm{~h}$.

An adsorbent of conjugated sponge of karaya gum and chitosan had been synthesized and used in the removal of anionic and cationic dyes from aqueous solutions [75]. Results from the investigation showed that the adsorbent presented an adsorption capacity of 
$33 \mathrm{mg} / \mathrm{g}$ for methyl orange and also $33 \mathrm{mg} / \mathrm{g}$ in the case of methylene blue. The aqueous $\mathrm{pH}$ value influenced the adsorption of methylene blue, decreasing it as the $\mathrm{pH}$ increased from 5 to 10. Methyl orange uptake responded well to the Langmuir isotherm, indicating adsorption on the homogeneous surface against methylene blue adsorption, which fitted to the Freundlich isotherm, indicative of an adsorption onto a heterogeneous surface. Both dyes in the concentration range of $10-50 \mathrm{mg} / \mathrm{L}$ followed the pseudo-second-order equation. Adsorption was caused by (i) electrostatic interaction between $\mathrm{SO}_{3}{ }^{-}$groups of methyl orange and $\mathrm{NH}_{3}{ }^{+}$groups in the adsorbent; in the case of methylene blue, (ii) the interactions were between $\mathrm{N}^{+}$groups in the dye and $\mathrm{COO}^{-}$groups present in the adsorbent. Desorption was carried out with $0.1 \mathrm{M}$ of $\mathrm{HCl}$ (methylene blue) or $0.1 \mathrm{M}$ of $\mathrm{NaOH}$ (methyl orange) and a slight but continuous decrease (six cycles) in the adsorption-desorption rates was observed.

In the race to find low-cost adsorbents, a non-toxic biosorbent possessing a highcharge density and thermal stability was prepared by using hexametaphosphate as an ionic cross-linker. The as-obtained chitosan microspheres were use in the removal of malachite green and anionic reactive red-195 from waters [76]. While the adsorption equilibrium was fixed at $120 \mathrm{~min}$ (malachite green) or $60 \mathrm{~min}$ (reactive red-195), the adsorption was best described in the $25-45^{\circ} \mathrm{C}$ range by the pseudo-second-order model, in addition to the Freundlich and Temkin isotherms. In studying the influence of the temperature on dye adsorption, the exothermic and non-spontaneous (malachite green), and endothermic and spontaneous (reactive red-195) nature of the adsorption processes was observed. No desorption data were included in this work.

Synthetic and functionalized amorphous silica, silica nanosheets, and silica nanoparticles, modified by hexadecyl trimethyl ammonium bromide and hexadecyl trimethoxysilane, were used to remove dyes from solutions [77]. The investigated dyes were malachite green, crystal violet, and bromophenol blue. In the case of malachite green, the dye uptake increased with the $\mathrm{pH}$ value from 3 to 9 , whereas for crystal violet and bromophenol blue, the adsorption was better in the 5-9 $\mathrm{pH}$ values range. Typical uptakes were $423 \mathrm{mg} / \mathrm{g}$ (malachite green), $409 \mathrm{mg} / \mathrm{g}$ (crystal violet), and $262 \mathrm{mg} / \mathrm{g}$ (bromophenol blue). Experimental data fitted to the pseudo-second-order and Freundlich models, attributable to the significant role of $\pi-\pi$ stacking. No desorption data were included in this work.

In the next investigation, a microporous anionic metal-organic framework, JUC-210, was synthesized using a spirobifluorene-based ligand and In(III) [78]. Due to its structure, which consisted of a two-fold interpenetrated pts framework with a large void space, the material was investigated to separate various dyes. The adsorbent showed a high selective adsorption towards methylene blue and in the presence of neutral red, Sudan I, Orange II, and methyl orange. The adsorption of methylene blue followed the Lagmuir and pseudo-second-order kinetic models, and its adsorption, due to its positive charge, was based on ion-exchange and size exclusion. The desorption step was not considered in this work.

Methylene blue and methyl orange were adsorbed using a three-dimensional graphene aerogel material, fabricated from graphene oxide sheets with ethylenediamine acting as a reducing agent [79]. Maximum adsorption capacities were $222 \mathrm{mg} / \mathrm{g}$ (methylene blue) and $167 \mathrm{mg} / \mathrm{g}$ (methyl orange). The adsorption followed the Langmuir isotherm and pseudosecond-order kinetic model, with the maximum adsorption reached at $\mathrm{pH} 6$ (methylene blue) or $\mathrm{pH} 3$ (methyl orange). Adsorption equilibrium was achieved at very different times: $250 \mathrm{~min}$ in the case of methyl orange or near $800 \mathrm{~min}$ for methylene blue. No desorption data appeared in this work.

A mixed compound of nitrilotriacetic acid $\beta$-cyclodextrin-chitosan was produced for the simultaneous removal of dyes and metals [80]. In this adsorption process, $\beta$ cyclodextrin cavities adsorbed methylene blue by host/guest contacts and the remaining functional groups acted as adsorption sites for methyl orange (and metal ions). Maximum adsorption capacities of the adsorbent were $133 \mathrm{mg} / \mathrm{g}$ (methyl orange) and $163 \mathrm{mg} / \mathrm{g}$ (methylene blue). The adsorption data fitted to Sips (methyl orange) and Langmuir (methy- 
lene blue) models, and both dyes followed the pseudo-second-order kinetic model. Desorption was accomplished with $\mathrm{HCl}$, ethanol, or nitric acid, followed by washing with deionized water. In binary solutions containing methylene blue and $\mathrm{Hg}(\mathrm{II})$, the removal efficiency for the dye was maintained nearly constant (95\%) after four cycles.

Melamine and cyanuric chloride were directly used to fabricate a covalent triazine framework through a polycondensation; due to its properties, including numerous basic nitrogen atoms (near $59 \% \mathrm{wt} \%$ ), the BET surface area $(670 \mathrm{~m} / \mathrm{g}$ ), and the hierarchical pore structure, the material was investigated as a potential adsorbent of anionic dyes, using the removal of Congo red as an example [81]. The maximum adsorption capacity was of $1581 \mathrm{mg} / \mathrm{g}$ at $30^{\circ} \mathrm{C}$, with the adsorption mechanism attributable to the electrostatic attraction and hydrogen bonding between the dye and the adsorbent. As can be seen from Table 7, the adsorbent lost its effectiveness as the $\mathrm{pH}$ value increased.

Table 7. Influence of the $\mathrm{pH}$ on the adsorption of anionic and cationic dyes.

\begin{tabular}{cccc}
\hline Dye & Type & pH & {$\left[\right.$ dye $_{\mathbf{a d}, \mathbf{m}, \mathbf{m g} / \mathbf{g}}$} \\
\hline Congo red & Anionic & 5 & 1581 \\
& & 12 & 600 \\
Rhodamine B & Cationic & 5 & 370 \\
& & 12 & 250 \\
\hline
\end{tabular}

Temperature: $30^{\circ} \mathrm{C}$. Time: $12 \mathrm{~h}$. Dye concentrations: $60 \mathrm{mg} / \mathrm{L}$. Adsorbent dosage: $30 \mathrm{mg} / \mathrm{L}$.

The adsorption of cationic dyes can be improved when mixed with Congo red, e.g., single cationic dye solutions of malachite green or methylene blue resulted in an adsorption rate of $57 \%$ or $16 \%$, respectively; however, the binary mixture of these with Congo red resulted in $100 \%$ (malachite green) or $92 \%$ (methylene blue) adsorption rates. This synergistic effect was attributed to (i) the preferential adsorption of Congo red onto the adsorbent surface, which reduced the surface charge and thus this surface was more adequate to adsorb cationic molecules, and (ii) to the fact that sulfonic groups in the Congo red molecule reacted with the positive groups (e.g., quaternary ammonium group) present in the cationic compound, enhancing their removal from the solution, i.e., Congo red acted as a bridge between the adsorbent and the cationic molecule. Congo red was desorbed with the use of a sodium chloride saturated ethanol solution for $4 \mathrm{~h}$, for which the adsorption efficacy decreased from $100 \%$ to $90 \%$ after six cycles. Moreover, monolithic aerogels were produced by incorporating the adsorbent into polyvinylidene fluoride and through a further casting in melamine resin foams.

The next reference investigated the removal of methylene blue and orange green by a series of adsorbents polymers [82]. The adsorption of methylene blue reached the equilibrium after $45 \mathrm{~min}$ at $\mathrm{pH} 6.86$ and $20^{\circ} \mathrm{C}$. This reference is unique because it included an approach to the cost of the adsorbents studied in the removal of dyes. Table 8 presents some of these results. No desorption data were included in this reference.

Table 8. Approximate costs in the removal of methylene blue from solutions using various adsorbents.

\begin{tabular}{ccc}
\hline Adsorbent & Adsorbent Cost, US Dollars & $\begin{array}{c}\text { Methylene Blue Capacity, } \\
\text { mol/g }\end{array}$ \\
\hline Wheat flour & $<5$ & 3.3 \\
Turmeric powder & 10 & 6.8 \\
Polyaniline & $25-30$ & 7.1 \\
Nano(Fe-Ni-Si) oxide & near 10 & 22 \\
\hline
\end{tabular}

Treatment of $1000 \mathrm{~L}$ of a synthetic solution containing $1 \times 10^{-5} \mathrm{M}$ dye.

Jute fiber was subjected to a chemical activation method to yield activated carbon fibers [9]. The as-prepared material was used to investigate its adsorbent properties against methylene blue and 4-nitrophenol. 
A foam, described as $\mathrm{GO} / \mathrm{g}-\mathrm{C}_{3} \mathrm{~N}_{4} / \mathrm{TiO}_{2}$, was prepared via hydrothermal treatment and freeze-drying methods [83]. Besides oil-water mixtures, this material was used to adsorb organic dyes such as rhodamine B, methylene blue, and methyl orange. Both rhodamine $B$ and methylene blue were adsorbed with efficiencies near $98 \%$, whereas in a mixture of methylene blue and methyl orange, the cationic dye was totally adsorbed by the foam but methyl orange was maintained in the solution. No desorption data were included in this investigation.

Hydrothermal procedures were used to fabricate coordination polymeric chains modified by polyoxometalate, $\mathrm{H}_{3} \mathrm{~K}_{2}\left[\mathrm{Ag}_{5}(\mathrm{DTB})_{5}\right]\left[\mathrm{SiW}_{12} \mathrm{O}_{40}\right]_{2} \cdot \mathrm{Cl}_{2} \cdot 8 \mathrm{H}_{2} \mathrm{O}$, where $\{\mathrm{DTB}=1,4-\mathrm{di}(1 \mathrm{H}-$ 1,2,4-triazol-1-yl)benzene\} [84]. In single solutions, the removal rate for crystal violet was $74 \%$ after $90 \mathrm{~min}$, and in the same time, $85 \%$ of methylene blue was removed from the solution. Using binary solutions, the material can separate methylene blue and crystal violet from methyl orange in a selective form; that is, separate cationic dyes from anionic ones. The data indicated that this adsorption was attributable to the sizes of the organic dyes. No desorption data were included in the manuscript.

A titanate-based material (peroxide sodium titanate, PST) was used as a precursor to fabricate three types of surface-charged surfactants: dodecyl dimethyl betaine (BS-PST), sodium dodecyl sulphate (SDS-PST), and dodecyltrimethyl ammonium chloride (DTACPST [85]. These were used to investigate the removal of contaminants such as methylene blue, acid red G, and ammonia nitrogen and phosphate. The batch experimentation showed that the DTAC-PST material had the best removal performance over methylene blue, though the maximum adsorption capacity was $82 \mathrm{mg} / \mathrm{g}$ (methylene blue) and $546 \mathrm{mg} / \mathrm{g}$ (acid red G). In simulated waters containing $50 \mathrm{mg} / \mathrm{L}$ of methylene blue and $50 \mathrm{mg} / \mathrm{L}$ of acid red G, in addition to the inorganic contaminants mentioned above, the dyes concentrations in the solution at the equilibrium were maintained below the limiting value of $10 \mathrm{mg} / \mathrm{L}$, marked by the discharge levels in China (GB, 18918-2002) by using the adsorbent and controlling the $\mathrm{pH}$ value: $2-4$ for acid red $\mathrm{G}$ or $2-10$ for methylene blue. Electrostatic attraction and ligand exchange were the mechanisms of methylene blue uptake onto the adsorbent, whereas in the case of acid red G, C- $\mathrm{N}^{+}$from the DTAC modification was responsible for the adsorption of the dye. The dye-loaded DTAC-PST could be regenerated by $0.5 \mathrm{M}$ of $\mathrm{NaOH}$ solutions, maintaining near $80 \%$ of its adsorption capacity after five cycles.

Methylenen blue and rhodamine B were removed from solutions by the use of porous $\mathrm{BN}$ nano/microrods [86]. The material also acted in a selective form towards cationic dyes in the case of binary mixtures of Congo red and the above cationic dyes. This selectivity was attributable to the synergistic effect of (i) the electrostatic and $\pi-\pi$ interactions; (ii) the size of the dye molecule; and (iii) the specific surface area and pore size of the adsorbent. The removal of the adsorbed dye from the adsorbent was not included in this investigation.

\section{Conclusions}

This review demonstrates that the subject regarding the removal of hazardous organic dyes from solutions is of considerable interest for numerous investigation groups and institutions around the world. The adsorbents used for this task contemplated the removal of solo anionic or cationic dyes, as well as the removal of mixtures of both types. These adsorbents presented different origins. Thus, one can find adsorbents based on metal composites and nanocomposites; magnetic or non-magnetic compounds; carbon-based compounds; metal-organic polymers; natural materials; silica-based compounds; organicbased compounds; MOF-based materials; graphene-based materials; and biomaterials, among others. In any case, the disparity, with respect to the dye uptake onto the adsorbent, is great. In this period of time, the removal of about 36 different organic dyes have been investigated; however, as can be seen from Table 9, the quantitative results showed by the papers greatly varied concerning the maximum dye adsorption capacity resulting from the experimental data. 
Table 9. Some quantitative results concerning the organic dyes' uptake onto different adsorbents.

\begin{tabular}{cccccccc}
\hline $\begin{array}{c}\text { Methylene } \\
\text { Blue }\end{array}$ & Reference & $\begin{array}{c}\text { Malachite } \\
\text { Green }\end{array}$ & Reference & $\begin{array}{c}\text { Methyl } \\
\text { Orange }\end{array}$ & Reference & $\begin{array}{c}\text { Congo } \\
\text { Red }\end{array}$ & Referene \\
\hline 12 & {$[40]$} & 140 & {$[38]$} & 6 & {$[61]$} & 89 & {$[73]$} \\
25 & {$[32]$} & 2000 & {$[59]$} & 133 & {$[80]$} & 140 & {$[17]$} \\
573 & {$[63]$} & & & 255 & {$[21]$} & 331 & {$[69]$} \\
1584 & {$[43]$} & & & 316 & {$[25]$} & 926 & {$[29]$} \\
1690 & {$[33]$} & & & 1146 & {$[26]$} & 1250 & {$[22]$} \\
1807 & {$[44]$} & & & 1409 & {$[19]$} & 1581 & {$[81]$} \\
\hline
\end{tabular}

(Concentrations in $\mathrm{mg} / \mathrm{g}$ ).

However, as it can be seen in Table 10, this review demonstrates that the experimental investigations published during the first six months of the 2021 year were mainly polarized in a limiting geographical zone. Effectively, the vast amount of these investigations came from Asia and within this continent, authors and institutions came from China, exhibiting great differences over others.

Table 10. Distribution of the papers published in the first six months of the 2021 year.

\begin{tabular}{cc}
\hline Zone & Percentage $^{\text {a }}$ \\
\hline Africa & 2.6 \\
America & 6.5 \\
Asia & 85.7 \\
Europe & 3.9 \\
Oceania & 1.3 \\
\hline a Over a total of 77 manuscripts. Distribution based on the address and affiliation of the corresponding author.
\end{tabular}

Considering that many of the investigations claimed a process to remove dyes, it was noted that from the papers published, an important 39\% of them did not present desorption results. In this context, the opinion of the reviewers is that this is less than acceptable because authors must realize that, as important as the adsorption of a given dye onto an adsorbent is, the release (desorption step) of the solute from the loaded adsorbent is equally important to recognize the real practical usefulness of the given adsorbent; that is, only with the adsorption step can one have $50 \%$ of the information necessary to judge the overall effectiveness of the adsorbent to remove a dye from solutions.

Though all the investigations were important to gain knowledge from an applied or even basic research point of view, in all the cases, the present reviewers detect that not one of the reported investigations mentioned what to do with the desorbed solution containing the desorbed dye, which presumably may have a greater dye concentration that the dye-bearing feed solutions, as normally the desorbed phase used lower volumes than the fed one. Thus, they become more concentrated in the dye and consequently are more hazardous or toxic than the initial ones.

Only one [20] of the reviewed manuscripts investigated the influence of the stirring speed on the dye uptake onto the adsorbent. This is an experimental variable often neglected by authors and may be of the same importance as others, e.g., $\mathrm{pH}$, temperature, dosages, etc., because, as also mentioned in [20], with the correct stirring speed applied on the system, the thickness of the solution boundary layer reaches a minimum and the adsorption maximizes. Authors must note that the influence of this variable on dye adsorption (or lack of) is not predictable and only can be known after experimentation. Considering the above, must one consider correcting the quantitative results given in the manuscripts.

In any case, the topic concerning the removal of organic dyes from solutions by means of adsorption methodologies is still of fascinating interest to many research groups and by no doubt the number of adsorbents to be used in this field is expected to expand. Consequently, the results, hopefully considering the above points, will continue to be published and fill our knowledge-base in this important environmental and sociological issue. 
Author Contributions: Conceptualization, F.J.A. and F.A.L.; writing-original draft preparation, F.J.A.; writing-review and editing, F.J.A. and F.A.L.; supervision, F.J.A. and F.A.L. All authors have read and agreed to the published version of the manuscript.

Funding: This research received no external funding.

Institutional Review Board Statement: Not applicable.

Informed Consent Statement: Not applicable.

Acknowledgments: We acknowledge support towards the publication fee by the CSIC Open Access Publication Support Initiative through its Unit of Information Resources for Research (URICI).

Conflicts of Interest: The authors declare no conflict of interest.

\section{References}

1. Costa, J.A.S.; De Jesus, R.A.; Santos, D.O.; Neris, J.B.; Figueiredo, R.T.; Paranhos, C.M. Synthesis, functionalization, and environmental application of silica-based mesoporous materials of the M41S and SBA-n families: A review. J. Environ. Chem. Eng. 2021, 9, 105259. [CrossRef]

2. Donga, C.; Mishra, S.B.; Abd-El-Aziz, A.S.; Mishra, A.K. Advances in graphene-based magnetic and graphene-based/TiO 2 nanoparticles in the removal of heavy metals and organic pollutants from industrial wastewater. J. Inorg. Organomet. Polym. Mater. 2021, 31, 463-480. [CrossRef]

3. Yap, P.L.; Nine, M.J.; Hassan, K.; Tung, T.T.; Tran, D.N.H.; Losic, D. Graphene-based sorbents for multipollutants removal in water: A review of recent progress. Adv. Funct. Mater. 2021, 31, 2007356. [CrossRef]

4. Gautam, R.K.; Goswami, M.; Mishra, R.K.; Chaturvedi, P.; Awashthi, M.K.; Singh, R.S.; Giri, B.S.; Pandey, A. Biochar for remediation of agrochemicals and synthetic organic dyes from environmental samples: A review. Chemosphere 2021, $272,129917$. [CrossRef]

5. Parmar, B.; Bisht, K.K.; Rajput, G.; Suresh, E. Recent advances in metal-organic frameworks as adsorbent materials for hazardous dye molecules. Dalton Trans. 2021, 50, 3083-3108. [CrossRef] [PubMed]

6. Yuan, N.; Gong, X.; Sun, W.; Yu, C. Advanced applications of Zr-based MOFs in the removal of water pollutants. Chemosphere 2021, 267, 128863. [CrossRef] [PubMed]

7. Thamer, B.M.; Aldalbahi, A.; Meera Moydeen, A.; Rahaman, M.; El-Newehy, M.H. Modified electrospun polymeric nanofibers and their nanocomposites as nanoadsorbents for toxic dye removal from contaminated waters: A review. Polymers 2021, 23, 20. [CrossRef]

8. Xiao, W.; Jiang, X.; Liu, X.; Zhou, W.; Garba, Z.N.; Lawan, I.; Wang, L.; Yuan, Z. Adsorption of organic dyes from wastewater by metal-doped porous carbon materials. J. Clean. Prod. 2021, 284, 124773. [CrossRef]

9. Yousuf, M.R.; Mahnaz, F.; Syeda, S.R. Activated carbon fiber from natural precursors: A review of preparation methods with experimental study on jute fiber. Desalin. Water Treat. 2021, 213, 441-458. [CrossRef]

10. Da'na, E.; Taha, A.; Hessien, M. Application of ZnO-NiO greenly synthesized nanocomposite adsorbent on the elimination of organic dye from aqueous solutions: Kinetics and equilibrium. Ceram. Int. 2021, 47, 4531-4542. [CrossRef]

11. Deng, F.; Liang, J.; Yang, G.; Huang, Q.; Dou, J.; Chen, J.; Wen, Y.; Liu, M.; Zhang, X.; Wei, Y. Direct generation of poly(ionic liquids) on mesoporous carbon via Diels-Alder and multicomponent reactions for ultrafast adsorptive removal anionic organic dye with high efficiency. J. Environ. Chem. Eng. 2021, 9, 104872. [CrossRef]

12. El Gaayda, J.; Akbour, R.A.; Titchou, F.E.; Afanga, H.; Zazou, H.; Swanson, C.; Hamdani, M. Uptake of an anionic dye from aqueous solution by aluminum oxide particles: Equilibrium, kinetic, and thermodynamic studies. Groundw. Sustain. Dev. 2021, 12, 100540. [CrossRef]

13. Fatima, B.; Siddiqui, S.I.; Nirala, R.K.; Vikrant, K.; Kim, K.-H.; Ahmad, R.; Chaudhry, S.A. Facile green synthesis of ZnO-CdWO 4 nanoparticles and their potential as adsorbents to remove organic dye. Environ. Pollut. 2021, 271, 116401. [CrossRef]

14. Fu, Q.; Lou, J.; Zhang, R.; Peng, L.; Zhou, S.; Yan, W.; Mo, C.; Luo, J. Highly effective and fast removal of Congo red from wastewater with metal-organic framework Fe-MIL-88NH2. J. Solid State Chem. 2021, 294, 121836. [CrossRef]

15. Galan, J.; Trilleras, J.; Zapata, P.A.; Arana, V.A.; Grande-Tovar, C.D. Optimization of chitosan glutaraldehyde-crosslinked beads for reactive blue 4 anionic dye removal using a surface response methodology. Life 2021, 11, 85. [CrossRef]

16. Guo, G.; Zhao, L.; Meng, L.; Liu, X. Structure and performances of three metal coordination polymers synthesized from 4, $4^{\prime}$-(phenylazanediy1) dibenzoic acid. J. Mol. Struct. 2021, 1227, 129053. [CrossRef]

17. Kuk, Y.; Ok, K.M. Novel enantiomorphic Pb-coordination polymers dictated by the corresponding chiral ligands, $[\mathrm{Pb}((\mathrm{R}, \mathrm{R})$ $\left.\mathrm{TBA})\left(\mathrm{H}_{2} \mathrm{O}\right)\right] \cdot 1.7 \mathrm{H}_{2} \mathrm{O}$ and $\left[\mathrm{Pb}((\mathrm{S}, \mathrm{S})-\mathrm{TBA})\left(\mathrm{H}_{2} \mathrm{O}\right)\right] \cdot 1.7 \mathrm{H}_{2} \mathrm{O}[\mathrm{TBA}=1,3,5$-triazin-2(1H)-one-4,6-bis(alanyl)]. Mater. Chem. Front. 2021, 5, 1330-1340. [CrossRef]

18. Li, D.; Chai, K.; Yao, X.; Zhou, L.; Wu, K.; Huang, Z.; Yan, J.; Qin, X.; Wei, W.; Ji, H. $\beta$-cyclodextrin functionalized SBA-15 via amide linkage as a super adsorbent for rapid removal of methyl blue. J. Colloid Interface Sci. 2021, 583, 100-112. [CrossRef] [PubMed] 
19. Li, J.; Huang, L.; Jiang, X.; Zhang, L.; Sun, X. Preparation and characterization of ternary Cu/ $\mathrm{Cu}_{2} \mathrm{O} / \mathrm{C}$ composite: An extraordinary adsorbent for removing anionic organic dyes from water. Chem. Eng. J. 2021, 404, 127091. [CrossRef]

20. Liu, M.; Wang, Z. Adsorption performance of reactive red $2 \mathrm{BF}$ onto magnetic $\mathrm{Zn}_{0.3} \mathrm{Cu}_{0.7} \mathrm{Fe}_{2} \mathrm{O}_{4}$ nanoparticles. Mater. Res. Express 2021, 8, 025014. [CrossRef]

21. Mendieta-Rodríguez, L.S.; González-Rodríguez, L.M.; Alcaraz-Espinoza, J.J.; Chávez-Guajardo, A.E.; Medina-Llamas, J.C. Synthesis and characterization of a polyurethane-polyaniline macroporous foam material for methyl orange removal in aqueous media. Mater. Today Commun. 2021, 26, 102155. [CrossRef]

22. Mubarak, M.; Islam, M.S.; Yoon, D.-Y.; Lee, J.H.; Park, H.J.; Bae, J.-S.; Lee, H.-J. Flower-like Mg/Fe-layered double oxide nanospheres with ultrahigh adsorption efficiency for anionic organic dyes. Colloids Surf. A Physicochem. Eng. Asp. 2021, 618, 126446. [CrossRef]

23. Nguyen, V.D.; Nguyen, H.T.H.; Vranova, V.; Nguyen, L.T.N.; Bui, Q.M.; Khieu, T.T. Artificial neural network modeling for Congo red adsorption on microwave-synthesized akaganeite nanoparticles: Optimization, kinetics, mechanism, and thermodynamics. Environ. Sci. Pollut. Res. 2021, 28, 9133-9145. [CrossRef]

24. Reghioua, A.; Barkat, D.; Jawad, A.H.; Abdulhameed, A.S.; Khan, M.R. Synthesis of Schiff's base magnetic crosslinked chitosanglyoxal $/ \mathrm{ZnO} / \mathrm{Fe}_{3} \mathrm{O}_{4}$ nanoparticles for enhanced adsorption of organic dye: Modeling and mechanism study. Sustain. Chem. Pharm. 2021, 20, 100379. [CrossRef]

25. Saghir, S.; Xiao, Z. Hierarchical mesoporous ZIF-67@LDH for efficient adsorption of aqueous Methyl Orange and Alizarine Red, S. Powder Technol. 2021, 377, 453-463. [CrossRef]

26. Saghir, S.; Xiao, Z. Synthesis of novel Ag@ZIF-67 rhombic dodecahedron for enhanced adsorptive removal of antibiotic and organic dye. J. Mol. Liq. 2021, 328, 115323. [CrossRef]

27. Sirajudheen, P.; Karthikeyan, P.; Ramkumar, K.; Nisheetha, P.; Meenakshi, S. Magnetic carbon-biomass from the seeds of Moringa oleifera@ $\mathrm{MnFe}_{2} \mathrm{O}_{4}$ composite as an effective and recyclable adsorbent for the removal of organic pollutants from water. J. Mol. Liq. 2021, 327, 114829. [CrossRef]

28. Sirajudheen, P.; Karthikeyan, P.; Vigneshwaran, S.; M.C, B.; Meenakshi, S. Complex interior and surface modified alginate reinforced reduced graphene oxide-hydroxyapatite hybrids: Removal of toxic azo dyes from the aqueous solution. Int. J. Biol. Macromol. 2021, 175, 361-371. [CrossRef]

29. Wang, Q.; Wang, X.; He, H.; Chen, W. Fabrication of hollow LDH nanocages using ZIF-67 template as superb adsorbent for anionic organic pollutant. J. Porous Mater. 2021, 28, 471-480. [CrossRef]

30. Xiong, Z.; Wang, Y.; Xie, X.; Li, H.; Yao, C. Synthesis of poly(cyclotriphosphazene-co-3,3'sulfonyldianilide) microspheres and their adsorption of anionic (congo red) dye. Heterocycles 2021, 102, 231-244. [CrossRef]

31. Yang, S.; Zhao, F.; Sang, Q.; Zhang, Y.; Chang, L.; Huang, D.; Mu, B. Investigation of 3-aminopropyltriethoxysilane modifying attapulgite for Congo red removal: Mechanisms and site energy distribution. Powder Technol. 2021, 383, 74-83. [CrossRef]

32. Adel, M.; Ahmed, M.A.; Mohamed, A.A. Synthesis and characterization of magnetically separable and recyclable crumbled $\mathrm{MgFe}_{2} \mathrm{O}_{4}$ /reduced graphene oxide nanoparticles for removal of methylene blue dye from aqueous solutions. J. Phys. Chem. Solids 2021, 149, 109760. [CrossRef]

33. Chen, M.; Shen, Y.; Xu, L.; Xiang, G.; Ni, Z. Highly efficient and rapid adsorption of methylene blue dye onto vinyl hybrid silica nano-cross-linked nanocomposite hydrogel. Colloids Surf. A Physicochem. Eng. Asp. 2021, 613, 126050. [CrossRef]

34. Cui, Z.; Lin, H.; Zeng, L.; Lu, J. A new functionalized POM-based MOF containing $1 \mathrm{D}\left[\mathrm{Mo}_{3} \mathrm{O}_{10}\right]_{n}{ }^{2 \mathrm{n}-}$ chains and the flexible bis(pyrazine)-bis(amide) ligand. Inorg. Chem. Commun. 2021, 126, 108493. [CrossRef]

35. Ebrahimi, A.K.; Sheikhshoaie, I.; Salimi, S.; Arkaban, H. In-situ facile synthesis of superparamagnetic porous core-shell structure for dye adsorption. J. Mol. Struct. 2021, 1228, 129797. [CrossRef]

36. Ehgartner, C.R.; Werner, V.; Selz, S.; Hüsing, N.; Feinle, A. Carboxylic acid-modified polysilsesquioxane aerogels for the selective and reversible complexation of heavy metals and organic molecules. Microporous Mesoporous Mater. 2021, 312, 110759. [CrossRef]

37. Feng, M.; Yu, S.; Wu, P.; Wang, Z.; Liu, S.; Fu, J. Rapid, high-efficient and selective removal of cationic dyes from wastewater using hollow polydopamine microcapsules: Isotherm, kinetics, thermodynamics and mechanism. Appl. Surf. Sci. 2021, 542, 148633. [CrossRef]

38. Guo, Y.; Mo, Y.; Wang, M.; Cui, H.; Tang, Y.; Sun, T. Green and facile synthesis of hierarchical ZnOHF microspheres for rapid and selective adsorption of cationic dyes. J. Mol. Liq. 2021, 329, 115529. [CrossRef]

39. Han, X.; Wang, Y.; Zhang, N.; Meng, J.; Li, Y.; Liang, J. Facile synthesis of mesoporous silica derived from iron ore tailings for efficient adsorption of methylene blue. Colloids Surf. A Physicochem. Eng. Asp. 2021, 617, 126391. [CrossRef]

40. Hizal, J.; Kanmaz, N.; Yılmazoğlu, M. Adsorption efficiency of sulfonated poly (ether ether ketone) (sPEEK) as a novel low-cost polymeric adsorbent for cationic organic dyes removal from aqueous solution. J. Mol. Liq. 2021, 322, 114761. [CrossRef]

41. Kubra, K.T.; Salman, M.S.; Znad, H.; Hasan, M.N. Efficient encapsulation of toxic dye from wastewater using biodegradable polymeric adsorbent. J. Mol. Liq. 2021, 329, 115541. [CrossRef]

42. Kubra, K.T.; Salman, M.S.; Hasan, M.N. Enhanced toxic dye removal from wastewater using biodegradable polymeric natural adsorbent. J. Mol. Liq. 2021, 328, 115468. [CrossRef]

43. Lei, Y.; Huang, Q.; Dou, J.; Huang, H.; Yang, G.; Deng, F.; Liu, M.; Li, X.; Zhang, X.; Wei, Y. Fast adsorptive removal of cationic organic dye by anionic group functionalized carbon nanotubes with high efficiency. Colloids Interface Sci. Commun. 2021, 40, 100328. [CrossRef] 
44. Li, H.; Huang, H.; Yan, X.; Liu, C.; Li, L. A calix[4]arene-crosslinked polymer for rapid adsorption of cationic dyes in water. Mater. Chem. Phys. 2021, 263, 124295. [CrossRef]

45. Li, J.; Wang, B.; Chang, B.; Liu, J.; Zhu, X.; Ma, P.; Sun, L.; Li, M. One new hexatungstate-based binuclear nickel(II) complex with high selectivity adsorption for organic dyes. J. Mol. Struct. 2021, 1231, 129674. [CrossRef]

46. Liou, T.-H.; Liou, Y.H. Utilization of rice husk ash in the preparation of graphene oxide based mesoporous nanocomposites with excellent adsorption performance. Materials 2021, 14, 1214. [CrossRef]

47. Liu, Q.; Yu, H.; Zeng, F.; Li, X.; Sun, J.; Li, C.; Lin, H.; Su, Z. HKUST-1 modified ultrastability cellulose/chitosan composite aerogel for highly efficient removal of methylene blue. Carbohydr. Polym. 2021, 255, 117402. [CrossRef]

48. Mallakpour, S.; Behranvand, V. Methylene blue contaminated water sanitization with alginate/compact discs waste-derived activated carbon composite beads: Adsorption studies. Int. J. Biol. Macromol. 2021, 180, 28-35. [CrossRef]

49. Mohanraj, J.; Durgalakshmi, D.; Saravanan, R. Water-soluble graphitic carbon nitride for clean environmental applications. Environ. Pollut. 2021, 269, 116172. [CrossRef]

50. Tran, N.M.; Ta, Q.T.H.; Sreedhar, A.; Noh, J.-S. $\mathrm{Ti}_{3} \mathrm{C}_{2}$ Tx MXene playing as a strong methylene blue adsorbent in wastewater. Appl. Surf. Sci. 2021, 537, 148006. [CrossRef]

51. Ngo, T.M.V.; Nguyen, T.H.L.; Mai, X.T.; Pham, T.H.N.; Nguyen, T.T.T.; Pham, T.D. Adsorptive removal of cationic dyes using hybrid material-based polyelectrolyte modified laterite soil. J. Environ. Chem. Eng. 2021, 9, 105135. [CrossRef]

52. Paredes-Quevedo, L.C.; González-Caicedo, C.; Torres-Luna, J.A.; Carriazo, J.G. Removal of a textile azo-dye (Basic Red 46) in water by efficient adsorption on a natural clay. Water Air Soil Pollut. 2021, 232, 4. [CrossRef]

53. Vigneshwaran, S.; Sirajudheen, P.; Nikitha, M.; Ramkumar, K.; Meenakshi, S. Facile synthesis of sulfur-doped chitosan/biochar derived from tapioca peel for the removal of organic dyes: Isotherm, kinetics and mechanisms. J. Mol. Liq. 2021, 326, 115303. [CrossRef]

54. Vigneshwaran, S.; Sirajudheen, P.; Karthikeyan, P.; Meenakshi, S. Fabrication of sulfur-doped biochar derived from tapioca peel waste with superior adsorption performance for the removal of Malachite green and Rhodamine B dyes. Surf. Interfaces 2021, 23, 100920. [CrossRef]

55. Wang, M.; Guo, Y.; Fu, X.; Cui, H.; Sun, T.; Tang, Y.; Liu, Q. Facile synthesis of novel $\mathrm{Zn}_{3}(\mathrm{OH})_{2} \mathrm{~V}_{2} \mathrm{O}_{7} \cdot 2 \mathrm{H}_{2} \mathrm{O}$ nanocables with excellent adsorption properties. Mater. Lett. 2021, 283, 128710. [CrossRef]

56. Wang, X.; Zhang, Y.; Shan, R.; Hu, H. Polydopamine interface encapsulating graphene and immobilizing ultra-small, active $\mathrm{Fe}_{3} \mathrm{O}_{4}$ nanoparticles for organic dye adsorption. Ceram. Int. 2021, 47, 3219-3231. [CrossRef]

57. Wu, X.-M.; Liu, L.-X.; Liu, L.; You, Z.-H.; Guo, H.-X.; Chen, Z.-X. Ultrasound assisted synthesis of nanoscale NH2-MIL-53(Fe) for the adsorption of dye. Jiegou Huaxue 2021, 40, 42-46. [CrossRef]

58. Yang, Z.; Liu, X.; Liu, X.; Wu, J.; Zhu, X.; Bai, Z.; Yu, Z. Preparation of $\beta$-cyclodextrin/graphene oxide and its adsorption properties for methylene blue. Colloids Surf. B Biointerfaces 2021, 200, 111605. [CrossRef]

59. Zhang, B.; Jin, Y.; Qi, J.; Chen, H.; Chen, G.; Tang, S. Porous carbon materials based on Physalis alkekengi L. husk and its application for removal of malachite green. Environ. Technol. Innov. 2021, 21, 101343. [CrossRef]

60. Ahmadipouya, S.; Heidarian, M.H.; Ahmadijokani, F.; Jarahiyan, A.; Molavi, H.; Moghaddam, F.M.; Rezakazemi, M.; Arjmand, M. Magnetic $\mathrm{Fe}_{3} \mathrm{O}_{4} @ U$ UiO-66 nanocomposite for rapid adsorption of organic dyes from aqueous solution. J. Mol. Liq. 2021, 322, 114910. [CrossRef]

61. Chen, X.; Li, S.-B.; Liu, Z.-Y.; Zhang, Y.-T. Solvent-directed assembly of Zr-based metal-organic cages for dye adsorption from aqueous solution. J. Solid State Chem. 2021, 296, 121998. [CrossRef]

62. Delpiano, G.R.; Tocco, D.; Medda, L.; Magner, E.; Salis, A. Adsorption of malachite green and alizarin red s dyes using fe-btc metal organic framework as adsorbent. Int. J. Mol. Sci. 2021, 22, 788. [CrossRef]

63. Ding, R.-D.; Li, D.-D.; Yu, J.-H.; Jia, M.-J.; Xu, J.-Q. Porous 3,4-di(3,5-dicarboxyphenyl)phthalate-based Cd ${ }^{2+}$ coordination polymer and its potential applications. Spectrochim. Acta-Part A Mol. Biomol. Spectrosc. 2021, 252, 119498. [CrossRef] [PubMed]

64. Dong, B.; Wang, W.-J.; Xi, S.-C.; Wang, D.-Y.; Wang, R. A carboxyl-functionalized covalent organic framework synthesized in a deep eutectic solvent for dye adsorption. Chem.-A Eur. J. 2021, 27, 2692-2698. [CrossRef]

65. Jamali, M.; Akbari, A. Facile fabrication of magnetic chitosan hydrogel beads and modified by interfacial polymerization method and study of adsorption of cationic/anionic dyes from aqueous solution. J. Environ. Chem. Eng. 2021, 9, 105175. [CrossRef]

66. Li, J.; Shi, C.; Bao, A. Design of boron-doped mesoporous carbon materials for multifunctional applications: Dye adsorption and $\mathrm{CO}_{2}$ capture. J. Environ. Chem. Eng. 2021, 9, 105250. [CrossRef]

67. Lim, S.; Kim, J.H.; Park, H.; Kwak, C.; Yang, J.; Kim, J.; Ryu, S.Y.; Lee, J. Role of electrostatic interactions in the adsorption of dye molecules by $\mathrm{Ti}_{3} \mathrm{C}_{2}$-MXenes. RSC Adv. 2021, 11, 6201-6211. [CrossRef]

68. Manabe, S.; Kiliyankil, A.V.; Takiguchi, S.; Kumashiro, T.; Fugetsu, B.; Sakata, I. Graphene nanosheets homogeneously incorporated in polyurethane sponge for the elimination of water-soluble organic dyes. J. Colloid Interface Sci. 2021, 584, 816-826. [CrossRef]

69. Masud, A.; Zhou, C.; Aich, N. Emerging investigator series: 3D printed graphene-biopolymer aerogels for water contaminant removal: A proof of concept. Environ. Sci. Nano 2021, 8, 399-414. [CrossRef]

70. Mousavi, D.V.; Ahmadipouya, S.; Shokrgozar, A.; Molavi, H.; Rezakazemi, M.; Ahmadijokani, F.; Arjmand, M. Adsorption performance of UiO-66 towards organic dyes: Effect of activation conditions. J. Mol. Liq. 2021, 321, 114487. [CrossRef] 
71. Muthukumaran, T.; Philip, J. Synthesis of water dispersible phosphate capped $\mathrm{CoFe}_{2} \mathrm{O}_{4}$ nanoparticles and its applications in efficient organic dye removal. Colloids Surf. A Physicochem. Eng. Asp. 2021, 610, 125755. [CrossRef]

72. Nazir, M.A.; Bashir, M.A.; Najam, T.; Javed, M.S.; Suleman, S.; Hussain, S.; Kumar, O.P.; Shah, S.S.A.; Rehman, A.U. Combining structurally ordered intermetallic nodes: Kinetic and isothermal studies for removal of malachite green and methyl orange with mechanistic aspects. Microchem. J. 2021, 164, 105973. [CrossRef]

73. Nguyen, D.T.C.; Dang, H.H.; Vo, D.-V.N.; Bach, L.G.; Nguyen, T.D.; Tran, T.V. Biogenic synthesis of MgO nanoparticles from different extracts (flower, bark, leaf) of Tecoma stans (L.) and their utilization in selected organic dyes treatment. J. Hazard. Mater. 2021, 404, 124146. [CrossRef]

74. Patel, U.; Parmar, B.; Patel, P.; Dadhania, A.; Suresh, E. The synthesis and characterization of Zn(II)/Cd(II) based MOFs by a mixed ligand strategy: A $\mathrm{Zn}(\mathrm{II}) \mathrm{MOF}$ as a dual functional material for reversible dye adsorption and as a heterogeneous catalyst for the Biginelli reaction. Mater. Chem. Front. 2021, 5, 304-314. [CrossRef]

75. Ramakrishnan, R.K.; Padil, V.V.T.; Wacławek, S.; Černík, M.; Varma, R.S. Eco-friendly and economic, adsorptive removal of cationic and anionic dyes by bio-based karaya gum—chitosan sponge. Polymers 2021, 13, 251. [CrossRef] [PubMed]

76. Raval, N.P.; Mukherjee, S.; Shah, N.K.; Gikas, P.; Kumar, M. Hexametaphosphate cross-linked chitosan beads for the eco-efficient removal of organic dyes: Tackling water quality. J. Environ. Manag. 2021, 280, 111680. [CrossRef] [PubMed]

77. Shen, T.; Mao, S.; Ding, F.; Han, T.; Gao, M. Selective adsorption of cationic/anionic tritoluene dyes on functionalized amorphous silica: A mechanistic correlation between the precursor, modifier and adsorbate. Colloids Surf. A Physicochem. Eng. Asp. 2021, 618, 126435. [CrossRef]

78. Shi, X.; Zu, Y.; Jiang, S.; Sun, F. An anionic indium-organic framework with spirobifluorene-based ligand for selective adsorption of organic dyes. Inorg. Chem. 2021, 60, 1571-1578. [CrossRef]

79. Trinh, T.T.P.N.X.; Nguyet, D.M.; Quan, T.H.; Anh, T.N.M.; Thinh, D.B.; Tai, L.T.; Lan, N.T.; Trinh, D.N.; Dat, N.M.; Nam, H.M.; et al. Preparing three-dimensional graphene aerogels by chemical reducing method: Investigation of synthesis condition and optimization of adsorption capacity of organic dye. Surf. Interfaces 2021, 23, 101023. [CrossRef]

80. Usman, M.; Ahmed, A.; Yu, B.; Wang, S.; Shen, Y.; Cong, H. Simultaneous adsorption of heavy metals and organic dyes by $\beta$-Cyclodextrin-Chitosan based cross-linked adsorbent. Carbohydr. Polym. 2021, 255, 117486. [CrossRef]

81. Wu, J.; Liu, J.; Wen, B.; Li, Y.; Zhou, B.; Wang, Z.; Yang, S.; Zhao, R. Nitrogen-rich covalent triazine frameworks for high-efficient removal of anion dyes and the synergistic adsorption of cationic dyes. Chemosphere 2021, 272, 129622. [CrossRef]

82. Yeamin, M.B.; Islam, M.M.; Chowdhury, A.-N.; Awual, M.R. Efficient encapsulation of toxic dyes from wastewater using several biodegradable natural polymers and their composites. J. Clean. Prod. 2021, 291, 125920. [CrossRef]

83. Zhan, B.; Liu, Y.; Zhou, W.-T.; Li, S.-Y.; Chen, Z.-B.; Stegmaier, T.; Aliabadi, M.; Han, Z.-W.; Ren, L.-Q. Multifunctional 3D $\mathrm{GO} / \mathrm{g}-\mathrm{C}_{3} \mathrm{~N}_{4} / \mathrm{TiO}_{2}$ foam for oil-water separation and dye adsorption. Appl. Surf. Sci. 2021, 541, 148638. [CrossRef]

84. Zhang, H.-Y.; Liu, L.; Wang, H.-J.; Sun, J.-W. Asymmetrical modification of Keggin polyoxometalates by sextuple Ag-N coordination polymeric chains: Synthesis, structure and selective separation of cationic dyes. J. Solid State Chem. 2021, 296, 121986. [CrossRef]

85. Zhang, W.; Yang, X.; Lin, C.; Feng, J.; Wang, H.; Yan, W. Insight into the effect of surfactant modification on the versatile adsorption of titanate-based materials for cationic and anionic contaminants. Chemosphere 2021, 269, 129383. [CrossRef]

86. Zhao, Z.; Bai, C.; An, L.; Zhang, X.; Wang, F.; Huang, Y.; Qu, M.; Yu, Y. Biocompatible porous boron nitride nano/microrods with ultrafast selective adsorption for dyes. J. Environ. Chem. Eng. 2021, 9, 104797. [CrossRef] 